\title{
The role of storm scale, position and movement in controlling urban flood response
}

\author{
Marie-claire ten Veldhuis ${ }^{1,2}$, Zhengzheng Zhou ${ }^{2,3,4}$, Long Yang ${ }^{2}$, Shuguang Liu ${ }^{4}$, and James Smith ${ }^{2}$ \\ ${ }^{1}$ Delft University of Technology, Watermanagement Department, Delft, 2628CN, the Netherlands \\ ${ }^{2}$ Princeton University, Hydrometeorology Group, Princeton, NJ 08544, USA \\ ${ }^{3}$ Tongji University, School of Ocean and Earth Science, Shanghai, 200092, China \\ ${ }^{4}$ UNEP-Tongji Institute of Environment for Sustainable Development Shanghai, Shanghai, 20002 China
}

Correspondence: Marie-claire ten Veldhuis (j.a.e.tenveldhuis@ tudelft.nl) and Zhengzheng Zhou

(zhouzhengzhengzzz@126.com)

Received: 3 April 2017 - Discussion started: 15 May 2017

Revised: 14 November 2017 - Accepted: 14 November 2017 - Published: 18 January 2018

\begin{abstract}
The impact of spatial and temporal variability of rainfall on hydrological response remains poorly understood, in particular in urban catchments due to their strong variability in land use, a high degree of imperviousness and the presence of stormwater infrastructure. In this study, we analyze the effect of storm scale, position and movement in relation to basin scale and flow-path network structure on urban hydrological response. A catalog of 279 peak events was extracted from a high-quality observational dataset covering 15 years of flow observations and radar rainfall data for five (semi)urbanized basins ranging from 7.0 to $111.1 \mathrm{~km}^{2}$ in size. Results showed that the largest peak flows in the event catalog were associated with storm core scales exceeding basin scale, for all except the largest basin. Spatial scale of flood-producing storm events in the smaller basins fell into two groups: storms of large spatial scales exceeding basin size or small, concentrated events, with storm core much smaller than basin size. For the majority of events, spatial rainfall variability was strongly smoothed by the flowpath network, increasingly so for larger basin size. Correlation analysis showed that position of the storm in relation to the flow-path network was significantly correlated with peak flow in the smallest and in the two more urbanized basins. Analysis of storm movement relative to the flow-path network showed that direction of storm movement, upstream or downstream relative to the flow-path network, had little influence on hydrological response. Slow-moving storms tend to be associated with higher peak flows and longer lag times. Unexpectedly, position of the storm relative to impervious
\end{abstract}

cover within the basins had little effect on flow peaks. These findings show the importance of observation-based analysis in validating and improving our understanding of interactions between the spatial distribution of rainfall and catchment variability.

\section{Introduction}

The interactions between spatial and temporal variability of rainfall and hydrological response characteristics have been the topic of numerous empirical and modeling studies in recent decades (Anquetin et al., 2010; Lobligeois et al., 2014; Morin et al., 2006; Segond et al., 2007; Syed et al., 2003; Tetzlaff and Uhlenbrook, 2005; Volpi et al., 2012; Yakir and Morin, 2011). They have shown that interactions depend on the complex interplay between rainfall variability and catchment heterogeneity in ways that remain poorly understood. This is the case in particular for urban catchments where strong variability in land-use, high degree of imperviousness and the presence of stormwater drainage and detention infrastructure increase the complexity of hydrological response (e.g. Bruni et al., 2015; Fletcher et al., 2013; Meierdiercks et al., 2010; Smith et al., 2005, 2013a; Yang et al., 2016).

Urbanization tends to be associated with higher peak flows induced by reduced infiltration rates on impervious surfaces and with shorter response times. (e.g. Rose and Peters, 2001; Cheng and Wang, 2002; Du et al., 2012; Huang et al., 2008). However, several studies have found mixed effects of urban- 
ization on peak flows and response times, associated with a combination of imperviousness and flood mitigation measures, especially for basins where urbanization has predominantly taken place after implementation of stormwater control legislation (e.g. Smith et al., 2013a; Hopkins et al., 2015; Miller et al., 2014). Niemczynowicz (1999) and Schilling (1991) pointed out the importance of spatially distributed rainfall information at high resolution to study response in urban basins. Thanks to the advances of weather radar, such information is becoming increasingly available (Krajewski and Smith, 2002; Berne and Krajewski, 2013), typically at $1 \mathrm{~km}$ spatial resolution (Smith et al., 2007), and in some cases down to less than $100 \mathrm{~m}$ (Otto and Russchenberg, 2011; Chen and Chandrasekar, 2015; Thorndahl et al., 2017). (Wright et al., 2014b) analyzed flow variability in three suburbanized catchments in relation to different radar rainfall products and found that storm event water balance and hydrological response times varied with the radar product used for analysis. Berne et al. (2004) derived relationships for critical rainfall resolution for urban hydrology, using high-resolution radar rainfall datasets over six basins in the Mediterranean region. They found that the temporal and spatial rainfall resolution required for urban hydrological analysis varied from about $5 \mathrm{~min}, 3 \mathrm{~km}$ for basins $\sim 10 \mathrm{~km}^{2}$, to about $3 \mathrm{~min}, 2 \mathrm{~km}$ for basins of $\sim 1 \mathrm{~km}^{2}$ scale. Radar rainfall data have been used in various studies in recent decades to drive hydrological models and sensitivity of urban hydrological response to spatial and temporal rainfall variability. Bruni et al. (2015) and Ochoa-Rodriguez et al. (2015) used rainfall data from a polarimetric rainfall radar, at $\sim 30-100 \mathrm{~m}$ and minute resolution to drive semidistributed hydrodynamic models of one and seven highly urbanized catchments, respectively, in northwestern Europe to study urban hydrological response for a range of rainfall input resolutions. They found that sensitivity of flows to rainfall variability increased for smaller basin sizes and that hydrological response was more sensitive to change in temporal than in spatial rainfall input resolution. Gires et al. (2012) quantified the impact of unmeasured small-scale rainfall variability on urban runoff for an urban catchment in London, by downscaling radar rainfall data from $1 \mathrm{~km}$ and $5 \mathrm{~min}$ resolution to a resolution 9-8 times higher in space and 4-1 times higher in time. Uncertainty in simulated peak flow associated with small-scale rainfall variability reached 25 and $40 \%$ respectively for frontal and convective events. Rafieeinasab et al. (2015) analyzed sensitivity of hydrological response to rainfall variability for five urban catchments of different sizes, located in the City of Arlington and Grand Prairie (US), using a distributed hydrological model. They found that while flow variability was better captured using higher resolution rainfall input, errors in reproducing flow by the models remained equally large, with peak flow over- and underestimations of more than $100 \%$.

(Wright et al., 2014a) analyzed hydrological response for four semiurbanized basins in Charlotte watershed, North Carolina, using a Gridded Surface Subsurface Hydrologic
Analysis (GSSHA) model to examine the effect of rainfall time and length scales on flood response. They found that peak flows in the larger basins $\left(\sim 50-100 \mathrm{~km}^{2}\right)$ were dominated by large-scale storms, while more concentrated organized thunderstorm systems dominated in the smaller basins $\left(\sim 7-30 \mathrm{~km}^{2}\right)$. They also identified limitations of this and similar modeling studies, where hydrologic response may be attributable to errors in radar rainfall estimates or to features that were omitted or poorly represented in the model, such as detention ponds, the spatial distribution of layered soils and, in particular, initial soil moisture.

Smith et al. (2002) used a data-driven approach to study relationships between temporal and spatial rainfall variability and hydrological response in urban basins. They introduced the concept of rainfall-weighted flow distance, representing storm position and movement relative to the flow-path network in the basin. In their study, they analyzed hydrological response in five semiurbanized basins in the US for five extreme flood-producing storms based on detailed radar rainfall and flow observation datasets. They found that fractional coverage of a basin by heavy rainfall is a key element of scale-dependent flood response: storm event scales, i.e. spatial (area, length) and temporal (duration) scales smaller than the basin scale (basins length, response time), lead to lower runoff ratios and flood peak compared to when scales of rainfall and basin are similar. Storm motion was found to be amplifying peak flow under particular conditions: storm motion from the lower basin to the upper basin on a timescale of approximately $2 \mathrm{~h}$ served to amplify peak discharge for the case of a large, $\sim 100 \mathrm{~km}^{2}$ basin, relative to other modes of storm motion. In Smith et al. (2005), spatial rainfall variability in relation to the flow-path network was analyzed for 25 flashflood-producing storms in a $14 \mathrm{~km}^{2}$ urban watershed. They found that spatial rainfall variability was strongly smoothed by the flow-path network, resulting in hydrological responses for storms with widely varying spatial rainfall variability being strikingly similar.

Other authors have used similar concepts to study hydrological response in natural basins. In an extensive study of 300 events over a $148 \mathrm{~km}^{2}$ basin in Arizona, Syed et al. (2003) found that runoff volume and peak were strongly correlated with areal coverage by the storm core $\left(>25 \mathrm{~mm} \mathrm{~h}^{-1}\right.$ rainfall intensity). The importance of the storm core's position increased with basin size, with storm cores positioned in the central portion of the watershed producing more runoff and higher flood peaks. Morin et al. (2006) found that the sensitivity of flood response (in terms of flood peak magnitude and peak timing) to spatial rainfall variability increased with storm intensity, which they attributed to high flow velocities during intense storms. Similar results were found by Lobligeois et al. (2014), who analyzed the influence of spatial rainfall variability on hydrological response in 181 catchments in France based on spatial rainfall variability, storm position and catchment-scale storm velocity indices. They found that flow simulations by hydrological 
models benefited from spatially distributed rainfall input for large catchments and strongly spatially distributed rainfall fields. Nicotina et al. (2008) analyzed rainfall variability in a numerical study for large basins up to several thousand square kilometers and found that spatial variability of a storm was more important than variability in total rainfall volume over the basins. This was attributed to the dominant influence of hillslope flow on scales typically smaller than the rainfall variability scale, smoothing differences in travel times to the basin outlet. Channel flow only became more important in very large basins $\left(>8000 \mathrm{~km}^{2}\right)$, leading to stronger sensitivity to spatial rainfall variability. Zoccatelli et al. (2011) analyzed rainfall coverage, storm position and movement relative to the flow-path network for five storms in five different basins in southeastern Europe. Based on a model sensitivity study, they found that peak timing error introduced by neglecting spatial rainfall variability ranged between 30 and $72 \%$ of the corresponding catchment response time. Nikolopoulos et al. (2014) analyzed the role of storm motion using radar rainfall data to drive two models of varying complexity. They found that storm motion did not play a significant role in generating hydrologic response for a large storm event, in basins sized $8-623 \mathrm{~km}^{2}$. Emmanuel et al. (2015) investigated the impacts of spatial rainfall variability on hydrological response using a model simulation approach and found significant dispersion in results obtained for events for different simulation scenarios, showing the need for studying larger sets of events to derive robust general conclusions. Modeling studies reported in the literature have remained inconclusive with respect to the interactions between rainfall and catchment scales (Ogden et al., 2011; Morin et al., 2006; Nicotina et al., 2008; Rafieeinasab et al., 2015). This emphasizes the importance of using field observations to corroborate preliminary conclusions drawn from model simulations.

In this study, we extracted a catalog of 279 flood events from 15 years of high-quality flow observations, in five nested (semi)urbanized basins in Charlotte region, North Carolina (US). By flood events we understand the set of events associated with the top five largest peak flows per year, on average. The term "flood response" is used to refer to hydrological response associated with these high flow events, on the (sub)catchment scale. In the catchments we investigated, it is hard to distinguish between "bank-full" flow and inundating flows, since channels and natural floodplains were heavily modified as a consequence of urbanization. As a result, what used to be considered bank-full flow in a natural channel could be considered flooding (of private properties, gardens) in the urbanized context (TurnerGillespie et al., 2003). Observational resources for the Charlotte metropolitan region are exceptionally rich (e.g. Smith et al., 2002; Wright et al., 2013). The region is covered by two National Weather Service WSR-88D (Weather Surveillance Radar-1988 Doppler) radar instruments, both of which were deployed in 1995. A dense network of rain gauges and stream gauges was installed by the US Geological Survey
(USGS) in 1995. We analyze the influence of spatial scale, position and movement of storms relative to the flow-path network as well as interactions with spatial distribution of imperviousness on urban flood response. We aimed to address the following questions.

- How does rainfall scale interact with basin scale in determining urban flood response? We use fractional coverage to express the relation between rainfall scale and basin scale and to investigate the dependencies of flood peak magnitude and lag time on rainfall scale.

- Does the position of a storm in relation to the flow-path network influence flood response? We use the concept of rainfall-weighted flow distance (RWD) to identify the position of a storm relative to the flow-path network and analyze whether storms concentrated in the upstream part of the catchment are associated with significantly different responses compared to storms concentrated in the center or near the basin outlet.

- How does storm direction and velocity in relation to the flow-path network influence flood response? We use first-order differences in RWD to characterize storm movement and investigate if storms passing over the basin in the downstream direction lead to significantly different hydrological responses compared to storms moving in the upstream direction and storms moving perpendicular to the main flow direction.

- How does the position of a storm in relation to the spatial distribution of imperviousness influence flood response?

This paper is organized as follows: in Sect. 2, the case study area, datasets and methods used in this study are introduced. Results are presented and discussed in Sect. 3, followed by summary and conclusions in Sect. 4 .

\section{Data and methods}

\subsection{Study region, rainfall and flow datasets}

The data used in the study were collected at five USGS stream gauging stations in Charlotte-Mecklenburg county, North Carolina. Gauging stations are located at the outlet of hydrological basins that range from 7.0 to $111.1 \mathrm{~km}^{2}$ in size. The area is largely covered by low- to high-intensity urban development, covering 60 to $100 \%$ of basin areas. The percentage of impervious cover varies from $25 \%$ in the least developed to $48 \%$ in the most urbanized basin covering the city center of Charlotte. Figure 1 shows a map with the location of the area, catchment boundaries and location of stream gauges used in the analysis. High-resolution $(30 \mathrm{~m})$ gridded datasets were used for terrain elevation (National Map of USGS, http://viewer.nationalmap.gov/), impervious cover, 

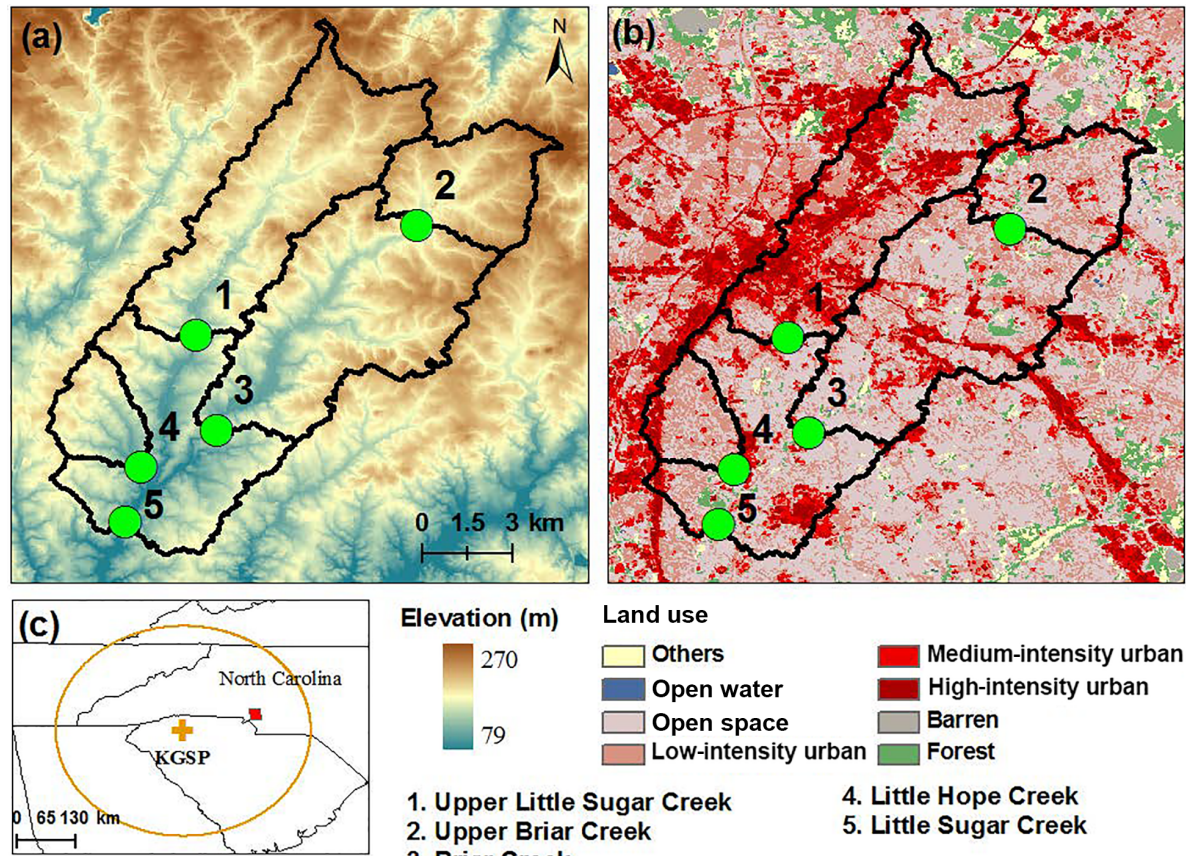

1. Upper Little Sugar Creek 2. Upper Briar Creek

4. Little Hope Creek 3. Briar Creek

Figure 1. Location of Little Sugar Creek catchment (c), topography (a), land use and land cover (b), and location and boundaries of subbasins, including locations of flow gauges and the location of rainfall radar.

land use and land cover (LULC, from National Land Cover Dataset NLCD, available at: http://www.mrlc.gov/).

The focus of this was Little Sugar Creek catchment, upstream of the flow gauge at Archdale, with a total drainage area of $111 \mathrm{~km}^{2}$. Additionally, we used data from basins nested within the main basin, sized 7.0, 13.3, 31.5 and $48.5 \mathrm{~km}^{2}$. Stream gage data were collected at 5 to $15 \mathrm{~min}$ intervals over the period 2001-2015. For this study, all flow data were linearly interpolated $1 \mathrm{~min}$ values and converted to UTC time. Gauges measure water depth using pressure transducers, using an accuracy standard set by the USGS Office of Surface Water for stage measurement at approximately 0.01 foot (ft) or 0.2 percent of the effective stage. Flows are derived from stage-discharge curves that were established based on protocols developed by USGS and include manual flow measurements during site visits performed by USGS staff. As part of this procedure, stage-discharge curves are checked and recalibrated during site visits several times per year. More information on gauge data and field measurements is available at http://waterdata.usgs.gov/nc/nwis. Flow datasets for the Charlotte region are of exceptionally high quality and consistency as data collection protocol and gauge locations have remained unchanged over decades.

A summary of basin characteristics in Little Sugar Creek catchment is provided in Table 1. (Sub)basin areas range from 7.0 to $111.1 \mathrm{~km}^{2}$, with impervious cover from 23.9 to $48.2 \%$ and urban land use (excluding parks and lawns) covering 47.1 to $79.1 \%$ of the basin area. Upper Little Sugar (Upper LSugar hereafter) is the most urbanized basin, cov- ered by the urban core of the city of Charlotte. Upper and lower Briar (hereafter Upper Briar and Lower Briar) are the least urbanized basins, with impervious cover of 23.9 and $24.7 \%$ respectively; Little Hope (LHope) is the smallest basin in size. Maximum flow distance along the flow-path network varies from $49 \mathrm{~km}$ for the smallest to $213 \mathrm{~km}$ for the largest basin. Basin compactness, computed as the ratio of basin area over perimeter squared, is highest for Little Hope and lowest for Upper LSugar, showing that the latter is the most elongated basin. Dams have been implemented in three of the basins, all for recreational purposes, according to the National Inventory of Dams (nid.usace.army.mil/cm_apex). Storage volume varies from approximately 0.1 to $2 \mathrm{~mm}$ (dam storage volume divided by basin area).

Based on data from the USGS flow datasets, we established a catalog of flood events, based on "peak-overthreshold" selection such that we have, on average, five events per year over the period 2001-2015. Since radar rainfall data were only available for the summer season, April to September, events were extracted exclusively for this period. Flood events are local maxima in discharge for which there is not a larger discharge in a time window of $12 \mathrm{~h}$ centered on the peak time. Events with incomplete rainfall or discharge data were excluded from the dataset. This resulted in a cata$\log$ of 50 to 69 storm events per basin (see Table 1).

Rainfall amounts were computed for the time period associated with each of the flood events, based on radar rainfall data. A total of 15 years (2001-2015) of high-resolution $\left(15 \mathrm{~min}, 1 \mathrm{~km}^{2}\right)$ Hydro-NEXRAD radar rainfall fields were 
Table 1. Summary of hydrological basins in the Little Sugar Creek catchment: basin area $\left(\mathrm{km}^{2}\right)$, imperviousness (\%), slope (-), land use coverage (high intensity, medium intensity, low intensity urban development) (\%), maximum flow distance (km), number of dams regulating stormwater flows (-), number of POT flood events used for analysis (-).

\begin{tabular}{llrrrrrrrrr}
\hline Name & $\begin{array}{l}\text { USGS } \\
\text { ID }\end{array}$ & $\begin{array}{r}\text { Drainage } \\
\text { area } \\
\left(\mathrm{km}^{2}\right)\end{array}$ & $\begin{array}{r}\text { Slope } \\
(-)\end{array}$ & $\begin{array}{r}\text { Max. flow } \\
\text { distance } \\
(\mathrm{km})(-)\end{array}$ & $\begin{array}{r}\text { Basin com- } \\
\text { pactness } \\
(\%)\end{array}$ & $\begin{array}{r}\text { Impervi- } \\
\text { ousness }\end{array}$ & $\begin{array}{r}\text { Land use coverage }(\%) \\
\text { high int. } \\
\text { med. int. } \\
\text { low int. }\end{array}$ & $\begin{array}{r}\text { No. of } \\
\text { dams } \\
(-)\end{array}$ & $\begin{array}{r}\text { No. of } \\
\text { events } \\
(-)\end{array}$ \\
\hline Little Hope & 02146470 & 7.0 & 2.2 & 49 & 2.6 & 32.2 & 9.3 & 9.4 & 48.5 & 0 \\
\hline $\begin{array}{l}\text { Upper } \\
\text { Briar }\end{array}$ & 0214642825 & 13.3 & 1.9 & 58 & 2.3 & 23.9 & 3.6 & 9.3 & 34.2 & 1 \\
\hline $\begin{array}{l}\text { Upper } \\
\text { Little Sugar }\end{array}$ & 02146409 & 31.5 & 2.2 & 128 & 1.4 & 48.2 & 22.5 & 24 & 32.6 & 0 \\
\hline $\begin{array}{l}\text { Lower } \\
\text { Briar }\end{array}$ & 0214645022 & 48.5 & 2.4 & 168 & 1.6 & 24.7 & 4.5 & 9.9 & 32.8 & 5 \\
\hline $\begin{array}{l}\text { Lower } \\
\text { Little Sugar }\end{array}$ & 02146507 & 111.1 & 2.4 & 213 & 1.6 & 32.0 & 10.3 & 14.1 & 32.8 & 54 \\
\hline
\end{tabular}

available for this study, based on volume scan reflectivity observations from the NWS-operated Weather Surveillance Radar 1988 Doppler (WSR-88D) radar in Greer, South Carolina (radar code KGSP, see Fig. 1c). The Hydro-NEXRAD processing system was developed to generate radar rainfall estimates for hydrologic applications by converting threedimensional polar-coordinate volume scan reflectivity fields from NWS WSR-88D radars into two-dimensional Cartesian surface rainfall fields (Krajewski et al., 2011). The standard convective rainfall-reflectivity $(Z-R)$ relationship ( $R=a Z^{b}$, where $a=0.017, b=0.714 ; R$ is rain rate in millimeters per hour, $Z$ is radar reflectivity in millimeters to the power six per cubic meter), a $53 \mathrm{dBZ}$ hail threshold, and several standard quality control algorithms are used (see Seo et al., 2011 for more details). No range correction algorithms are used in this study. The dataset has been extensively validated in Wright et al. (2014b) and used for rainfall frequency analysis in Wright et al. (2013). Mean field bias correction of the radar rainfall is done on the daily scale using 71 rain gages from the Charlotte rain gauge network (CRN) (see Wright et al., 2014b). Radar-based rainfall estimates captured rainfall variability on timescales of 5-15 min based on the sampling resolution of the radar beam, and space scales of $1 \mathrm{~km}^{2}$. We used rainfall data at a temporal resolution of $15 \mathrm{~min}$ to avoid sensitivity to sampling error on the 5 min timescale. Radar rainfall data were spatially resampled at $30 \mathrm{~m}$ resolution using inverse-distance interpolation between radar pixel centroids, to enable computation of rainfall redistribution relative to the flow-path network and imperviousness, within the radar pixel (as will be explained in the next section). Basin-average rainfall rates were also computed, based on spatial aggregation of rainfall values over $1 \mathrm{~km}^{2}$ pixels within the catchment boundaries of the individual basins (percent of each $1 \mathrm{~km}^{2}$ grid in the basin was computed for pixels overlapping catchment boundaries). While 15 min estimates derived from 5 min radar sampling may smooth some of the rainfall variability, especially for fastmoving storms, they sufficiently capture the rainfall information relevant for this study, i.e. minimum, mean and maximum distance of storms relative to the outlet and movement of storms relative to the flow-path network.

\subsection{Methods}

\subsubsection{Hydrograph and basin average rainfall characteristics}

The following rainfall metrics were defined per event, based on basin-average rainfall rates derived from radar rainfall data at $15 \mathrm{~min}, 1 \mathrm{~km}^{2}$ resolution.

- Basin-average rainfall rate $\left(\mathrm{mm} \mathrm{h}^{-1}\right)$ :

$R_{\mathrm{b}}(t)=\int_{0}^{T} R(t, x) \mathrm{d} x$,

where $R_{\mathrm{b}}(t)$ is the basin-average rainfall rate at times $t$ $\left(\mathrm{mm} \mathrm{h}^{-1}\right) ; R(t, x)$ is the rain rate at pixel $x\left(1 \times 1 \mathrm{~km}^{2}\right)$ at time $t$ (time step is $15 \mathrm{~min}$ ), and $T$ is the time period of the selected event, from $12 \mathrm{~h}$ before the time of the maximum peak flow for a storm event until $12 \mathrm{~h}$ after the time of peak flow.

- Rainfall duration $R_{\mathrm{d}}$ (hours), duration of rainfall above a minimum threshold of $1 \mathrm{~mm} \mathrm{~h}^{-1}$ within the rainfall event:

$$
\begin{aligned}
R_{\mathrm{d}} & =\int_{0}^{T} I\left(R_{\mathrm{b}}(t)>1\right) \mathrm{d} t, \text { where } I\left(R_{\mathrm{b}}(t, x)>0\right) \\
& =\left\{\begin{array}{l}
1 \text { for } R_{\mathrm{b}}(t, x)>1 \mathrm{~mm} \mathrm{~h}^{-1} \\
0 \text { otherwise. }
\end{array}\right.
\end{aligned}
$$


- Total rainfall depth per event (mm):

$$
R_{\mathrm{b}, \mathrm{tot}}=\int_{0}^{T} R_{\mathrm{b}}(t)
$$

- Maximum 15 min rainfall intensity $\left(\mathrm{mm} \mathrm{h}^{-1}\right)$ :

$$
R_{\mathrm{b}, \max }=\max \left\{R_{\mathrm{b}}(t): t \in[0, T]\right\} .
$$

The following metrics were used to analyze relationships between rainfall and hydrologic response; flow values were normalized by basin area and expressed in cubic meters per second per square kilometer $\left(\mathrm{m}^{3} \mathrm{~s}^{-1} \mathrm{~km}^{-2}\right)$, to allow comparison among different basins.

- Maximum normalized peak flow $\left(\mathrm{m}^{3} \mathrm{~s}^{-1} \mathrm{~km}^{-2}\right)$ :

$$
Q_{\max }=\max \left\{Q(t) A^{-1}: t \in[0, T]\right\},
$$

where $Q$ is the instantaneous flow observation, at $1 \mathrm{~min}$ intervals $\left(\mathrm{m}^{3} \mathrm{~s}^{-1}\right) ; A$ is the basin area $\left(\mathrm{km}^{2}\right)$.

- Total normalized runoff volume $\left(\mathrm{m}^{3}\right)$ :

$$
Q_{\mathrm{tot}}=\int_{0}^{T} Q(t) A^{-1} \mathrm{~d} t .
$$

- Flood event duration (hours): $T_{Q}$, defined as the interval between the time when the unit hydrograph continuously rises above 0.05 and falls below $0.01 \mathrm{~m}^{3} \mathrm{~s}^{-1} \mathrm{~km}^{-2}$. Thresholds were established based on visual inspection of the hydrographs and work well for flood events with a single peak (or events separated from other flood peaks by at least $6 \mathrm{~h}$ ). For flood events with multiple peaks (i.e. flood peaks that are either preceded or followed by another flood peak within a short time, e.g. $1 \mathrm{~h}$ ), these thresholds can result in anomalously long event durations that are not representative of hydrological response behavior. For these events, we manually determined the start and end time for each of the "multi-peak" events by visually inspecting the hydrographs. We further checked the duration for "singlepeak" events through visual inspections, to ensure consistency in the definition of event duration.
- Lag time (hours): $T_{1}$, defined as the time difference between basin-average rainfall peak and maximum peak flow, computed from the time distance between the time of peak flow and time of basin-average maximum rainfall intensity during the preceding $12 \mathrm{~h}$ time period. In our initial analyses, we used two methods to compute lag times, based on peak-to-peak and on distance between centroids of hyetograph and hydrograph. The latter resulted in a large number of negative lag time values, associated with events with multiple rainfall and/or peak flows. After visual inspection of hyetographs and hydrograph peaks, we decided that peak-to-peak time gave a better representation of the response between rainfall and peak flows for most events, and hence we decided to stick to this lag time definition in our analyses.

- Runoff ratio (-): normalized runoff divided by total basin-average rainfall over the duration of the flood event $\left(T_{Q}\right)$.

- Peak ratio (-): normalized peak flow (flow divided by basin area) divided by rainfall peak intensity.

\subsubsection{Rainfall spatial characteristics: spatial variability, fractional coverage and rainfall-weighted flow distance}

We used fractional coverage of the basin by rainfall above a given threshold to analyze the influence of rainfall scale in relation to basin scale on hydrological response. Additionally we used the concept of rainfall-weighted flow distance, as first introduced by Smith et al. (2002). RWD provides a representation of rainfall variability relative to a distance metric imposed by the flow-path network. The methodology has been used in multiple previous studies (Smith et al., 2002, 2005; Zoccatelli et al., 2011; Nikolopoulos et al., 2014; Emmanuel et al., 2015). It represents the position of a storm relative to the flow-path network and is used to analyze how storm position and movement influence hydrological response.

Rainfall fractional coverage (-) was computed as follows:

$R_{c}(t)=\max \left\{\frac{1}{A} \int_{A} I(R(t, x)) \mathrm{d} x\right\}$,

where $I(R(t, x))$ is the indicator function and equals 1 when $R(t, x) \geqslant r$ or 0 otherwise; $R_{c}(t)$ is the maximum portion of basin area receiving rainfall equal to or exceeding $r \mathrm{~mm} \mathrm{~h}^{-1}$ rainfall. We used a threshold of $r=25 \mathrm{~mm} \mathrm{~h}^{-1}$, representative of high-intensity rainfall. This threshold corresponds with the 1 in threshold that is used by the flood hazard community in US, specifically the National Weather Service, as an index for potential flash flooding. It has also been used previously in the literature to investigate the influence of storm core versus overall rainfall (e.g. Syed et al., 2003). 
Rainfall-weighted flow distance $(\operatorname{RWD}(t)$, in $\mathrm{m})$ was computed as follows:

$\operatorname{RWD}(t)=\int_{A} w(t, x) \mathrm{d}(x) \mathrm{d} x$,

where distance function $\{\mathrm{d}(x) ; x \in A\}$ is the flow distance from point $x$ within the basin to the outlet of the basin and $w(t, x)$ is the rainfall weight function:

$w(t, x)=\frac{R(t, x)}{\int_{A}} R(t, x) \mathrm{d} x$.

RWD is normalized by maximum flow distance in the network, as follows:

$D(t)=\frac{1}{d_{\max }} \int_{A} w(t, x) \mathrm{d}(x) \mathrm{d} x$,

where $D(t)$ is the rainfall-weighted flow distance, normalized by maximum flow distance $(-), d_{\max }=\{\mathrm{d}(x) ; x \in A\}$, maximum flow distance in the flow-path network $(\mathrm{m})$.

The random variable $D(t)$ takes values from 0 to 1 : low values of $D(t)$ are associated with rainfall that is spatially concentrated near the outlet, high values with rainfall concentrated near the headwaters of the basin. For uniformly distributed rainfall, all weights across the basin are equal and $D(t)$ represents the mean flow distance imposed by the flowpath network:

$\bar{d}=\int_{A} \mathrm{~d}(x) \mathrm{d} x$.

Normalized, rainfall-weighted flow distances were computed per time step as well as for the total accumulated rainfall per storm event. The first provides information on storm movement over the basin relative to the flow-path network and combines both temporal and spatial rainfall variation (Smith et al., 2002), while the latter focuses on the spatial aspect of rainfall distribution, summarizing it for the total accumulated rainfall per storm event (Smith et al., 2005).

RWD dispersion was computed, to provide an indication of whether spatial rainfall variability as imposed by the flowpath network is unimodal or multimodal. The normalized RWD dispersion (-) was defined as follows (Smith et al., 2005).

$S(t)=\frac{1}{\bar{s}}\left\{\int_{A} w(t, x)[\mathrm{d}(x)-\bar{d}]^{2} \mathrm{~d} x\right\}^{\frac{1}{2}}$

where $\bar{s}$ is the dispersion for uniform rainfall:

$\bar{s}=\left\{\int_{A}[\mathrm{~d}(x)-\bar{d}]^{2} \mathrm{~d} x\right\}^{\frac{1}{2}}$.
RWD dispersion takes the value 1 for uniform rainfall; values below 1 are associated with unimodal spatially distributed rainfall and values above 1 represent multimodal spatially distributed rainfall peaks in relation to the flow-path network.

To further investigate the influence of spatial distribution of urbanization on urban flood response, we computed normalized RWD strictly for pixels with impervious cover larger than $80 \%$, classified as high-intensity development in the NLCD dataset. Thus, imperviousness-weighted, normalized, rainfall-weighted flow distance $\left(D_{I}(t)\right)$ was computed as follows:

$D_{I}(t)=\frac{1}{d_{\max }} \int_{A} I(x) w(t, x) \mathrm{d}(x) \mathrm{d} x$,

where $I(x)$ is an impervious indicator and takes value 1 for pixels with impervious cover $>80 \%$ and 0 for pixels with impervious cover $<80 \%$.

\subsubsection{Summary statistics and correlation analysis}

Metrics associated with normalized RWD are sensitive to the length of the time window over which they are computed (Smith et al., 2002; Nikolopoulos et al., 2014). We used a range of time windows of $x$ h rainfall, $x$ varying from 0.5 to $3 \mathrm{~h}$, corresponding to the timescales of storm duration and lag time for the largest two basins (median storm durations 3 and $3.5 \mathrm{~h}$, median lag times 1.7 and $2.0 \mathrm{~h}$ respectively). Results based on a $2 \mathrm{~h}$ window are shown in Sect. 3. The time window was centered over the time of event-maximum rainfall intensity. The following summary statistics were retained for normalized RWD: mean, minimum, maximum, coefficient of variation $(\mathrm{CV})$ and gradient as well as RWD for eventtotal accumulated rainfall. We analyzed time-varying spatial coverage by the storm core $\left(>25 \mathrm{~mm} \mathrm{~h}^{-1}\right), \Delta R_{\mathrm{cov}} / \Delta t$, in relation to basin-average rainfall $\Delta R / \Delta t$ to see how much of change in rainfall intensity is associated with change in storm core coverage of the basin. We analyzed $\Delta R / \Delta t$ versus $\Delta \mathrm{RWD} / \Delta t$ to see how change in rainfall intensity relates to movement of the storm relative to the flow-path network. Correlation analyses were performed for all combinations of metrics associated with basin-average rainfall, flow hydrograph, spatial rainfall variability and imperviousness distribution, based on Spearman rank correlations. Correlations were tested for significance at the $5 \%$ level ( $p$ value $>0.05$, based on $t$ test).

\section{Results and discussion}

\subsection{Rainfall and hydrograph characteristics of the selected events}

In Fig. 2, box plots of rainfall and flow characteristics are shown for the catalog of selected events, for the five basins. 
(a)
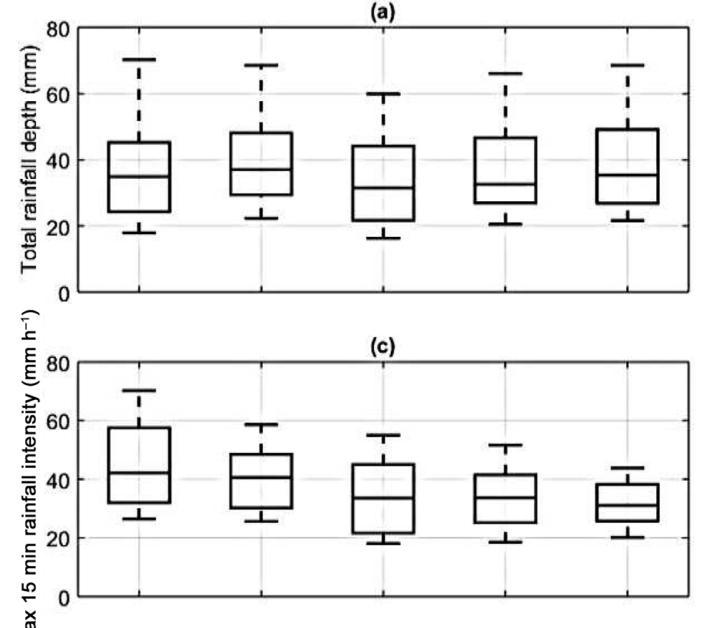

$\stackrel{\times}{\stackrel{x}{\pi}}$

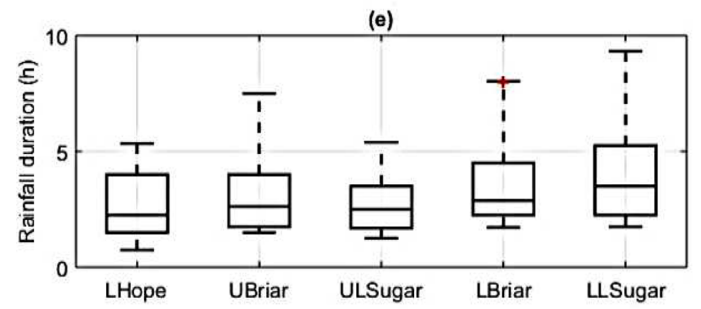

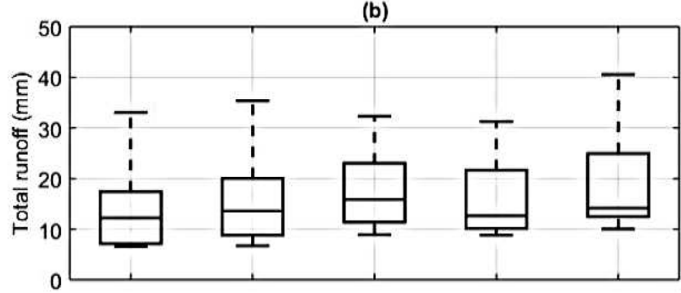

(d)
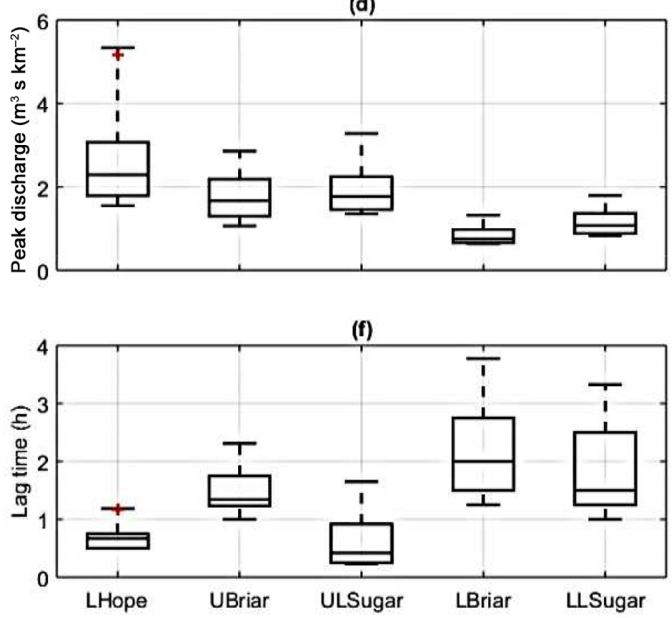

Figure 2. Box plots showing 10, 25, 50, 75 and $90 \%$ quantiles of characteristic rainfall and flow values for all events, per basin: total basinaverage rainfall depth (a), total normalized runoff volume $(\mathrm{mm})(\mathbf{b})$, max $15 \mathrm{~min}$ rainfall intensities $\left(\mathrm{mm} \mathrm{h}^{-1}\right)(\mathbf{c})$, normalized peak flows $\left(\mathrm{m}^{3} \mathrm{~s}^{-1} \mathrm{~km}^{-2}\right)(\mathbf{d})$, rainfall duration in hours (e), lag time (f). Box plots are based on 50 to 69 events per basin, as listed in Table 1.

The plots show that basin-average rainfall depth was of the same order of magnitude for all basins, with median values varying between 32.2 and $37.0 \mathrm{~mm}$. Runoff volumes are slightly lower for the smallest two basins in terms of their median values and less skewed. Peak rainfall intensities show stronger variation with basin size: median for peak $15 \mathrm{~min}$ rainfall intensity decreases from $41.7 \mathrm{~mm} \mathrm{~h}^{-1}$ for the smallest to $31.2 \mathrm{~mm} \mathrm{~h}^{-1}$ for the largest basin. Peak rainfall intensity varied by factor of 10 approximately across the set of selected peak events per basin $\left(9.5\right.$ to $87.6 \mathrm{~mm} \mathrm{~h}^{-1}$ for Lower LSugar; 9.3 to $83.2 \mathrm{~mm} \mathrm{~h}^{-1}$ for Lower Briar; 9.7 to $91.7 \mathrm{~mm} \mathrm{~h}^{-1}$ for Upper LSugar; 8.8 to $90.7 \mathrm{~mm} \mathrm{~h}^{-1}$ for Upper Briar; 10.4 to $118.5 \mathrm{~mm} \mathrm{~h}^{-1}$ for LHope). Figure $2 \mathrm{~d}$ shows large differences in peak flows between the basins, as indicated by $25-75$ and $10-90 \%$ ranges per basin. Lower Briar has lowest median normalized peak flows and narrowest quantile ranges, tied to a combination of large area size and low impervious cover compared to other basins, resulting in strongly smoothed flood response. The smallest basin, LHope, has a strongly skewed peak flow distribution, with the highest median as well as the largest quantile ranges of normalized peak flow values compared to the other basins. The lowest flow variability is found for the most urbanized basin (size $31.5 \mathrm{~km}^{2}$ ), which suggests a smoothing effect of imperviousness on flow variability. Upper LSugar, the most impervious basin, shows a high median peak flow value rel- ative to its basin size and quantile ranges similar to the much smaller UBriar basin. This is confirmed by coefficient of variation values of the flow distributions per basin: 0.37 and 0 . 46 for Upper and Lower LSugar; 0.65, 0.46 and 0.44 for LHope, Upper and Lower Briar. Similar results were found for a wider range of basins in this region in (Ten Veldhuis and Schleiss, 2017), who concluded that for the basins in the Charlotte catchment, flow regulation and peak flow restrictions induced by capacity constraints result in an overall effect of peak flow reduction associated with urbanization. The only quantitative information available to us about stormwater infrastructure in the Charlotte catchment is the number of dams, which is low for all 5 catchments $(0,1,0,5$ and 8 for the smallest to largest catchment). In a recent study by (Bell et al., 2016), additional information was collected for basins in this region. They computed the percentage area of mitigated area by detention structures: 5.5, 5.8 and 3.2\% for Little Hope, Upper Briar and Upper Little Sugar, respectively. These numbers show that the impact of detention structures on hydrological response is likely to be very small.

Flow peaks for our event catalog (maximum flow peaks per basin were 3.4 and $10.4 \mathrm{~m}^{3} \mathrm{~s}^{-1} \mathrm{~km}^{-2}$, respectively) were associated with 100-year return periods in 1990 and 1992, respectively, decreasing to 8 and 20 years in 2007, following (Villarini et al., 2009), who reported flood frequency distributions for Lower LSugar Creek and for LHope Creek, based 
on a generalized additive model fitted to annual flood peaks in these 2 basins. For rainfall, we compared return intervals of maximum 15 min rainfall intensities (over $1 \times 1 \mathrm{~km}^{2}$ with point rainfall frequency estimates provided by NOAA (NOAA, 2017); no frequency estimates were available on a $1 \times 1 \mathrm{~km}^{2}$ scale. Maximum values per event varied from 8.8 . to $132 \mathrm{~mm} \mathrm{~h}^{-1}$, associated with return intervals of less than 1 year up to 25 years on the point scale.

Rainfall duration varied from approximately 0.5 to $14 \mathrm{~h}$, representing a wide range from concentrated, single-peak events to prolonged, multi-peak events (Fig. 2e). Distributions show large quantile ranges ( 2.5 to $4 \mathrm{~h}, 25-75 \%$ range) and are highly skewed. Values in the upper percentiles were mainly associated with storm events with multiple rainfall peaks. Lag times (Fig. 2f), computed as time between maximum rainfall intensity and peak flow, are strongly tied to a combination of basin area size and impervious cover. Upper LSugar, the most urbanized basin, has the shortest median lag time ( $26 \mathrm{~min})$; the two largest basins have median lag times of 1.7 and $2 \mathrm{~h}$, whereas Lower LSugar has a slightly shorter median lag time than Lower Briar, despite its larger size. This confirms findings in an earlier study by Smith et al. (2002), who found that peaks at Lower LSugar are mostly linked to discharge from the highly urbanized Upper LSugar basin. Lag time values in the upper percentiles are generally associated with multi-peak events, where multiple rainfall peaks caused one or more peak flows over a prolonged period of time. Runoff ratios vary mainly with imperviousness degree: the largest median runoff ratio was found for Upper LSugar (0.51), followed by Lower LSugar (0.44), Lower Briar (0.38) and the two smallest basins, Upper Briar (0.35) and LHope (0.34). Variability in runoff ratio, expressed in terms of coefficient of variation, is low for Upper and Lower LSugar basins compared to the other basins (figure not shown). This effect is even stronger for peak-to-peak ratios: variability in terms of $\mathrm{CV}$ is very low for the more impervious basins $(0.5$ and 0.6 respectively for Upper and Lower LSugar) compared to the other basins (CV values 5.1, 4.2 and 3.7 for LHope, Upper and Lower Briar, respectively).

\subsection{Spatial rainfall variability and fractional basin coverage}

Spatial rainfall variability was analyzed based on the coefficient of variation of rainfall intensities per time step. Mean $\mathrm{CV}$ values vary from 1.24 for the smallest to 3.51 for the largest basin, showing that rainfall tends to be more spatially uniform for smaller basins compared to larger basins. Spatial variability is high compared to temporal rainfall variability based on basin-average rainfall, where $\mathrm{CV}$ values vary between 0.94 and 1.03 (no clear relation with basin size). This is partially a result of the difference in aggregation scales: basin-average rainfall is aggregated over 7 to $111 \mathrm{~km}^{2}$ and $15 \mathrm{~min}$, while spatially variable rainfall is aggregated over $1 \mathrm{~km}^{2}$ and several hours of rainfall duration.
Additionally, spatially varied rainfall data include far more zero values, which leads to strongly skewed distributions, as is confirmed by large differences between mean and median, while these differences are small for temporal rainfall variability. Still, these results show that rainfall for the selected flood events tends to be highly spatially variable. Moreover, spatial variability changes over the duration of events, more strongly so for the larger than for the smaller basins. This is a characteristic of hydroclimatic conditions in this region northeast of the Appalachians, as confirmed for instance by Zhou et al. (2017). Similar results were found by Lobligeois et al. (2014), who analyzed spatial variability of storm events associated with the largest 20 flood events in 181 basins in France. They showed that spatial rainfall variability was strongly dependent on hydroclimatic regions, with high variability occurring in the Mediterranean area, associated with summer convective storms, and low variability over much of the northern and western regions of France.

Figure 3 shows box plots and empirical histograms of fractional rainfall coverage, i.e. the maximum percentage of basin area covered by rainfall intensities larger than $25 \mathrm{~mm} \mathrm{~h}^{-1}$ during storm events, representing the most intense core of the storm. The box plots show that storm cores exceed basin scale for 43 and $23 \%$ of the storms in the two smallest basins ( 7 and $13.3 \mathrm{~km}^{2}$, respectively). For the larger basins this decreases to 10,4 and $2 \%$ (for basin sizes $31.5,48.5$ and $111.1 \mathrm{~km}^{2}$, respectively). Similar results were shown by Smith et al. (2002) and Syed et al. (2003) for the same range of (sub)basin sizes, for 5 storms using radar rainfall data and for 300 summer storms in Arizona using interpolated rain gauge data, respectively. Another interesting feature appears in the empirical histograms: for the smaller basins, fractional coverage values tends to be either small compared to basin size (coverage 0-20\%) or approaching basin size (coverage 80-100\%). Zhou et al. (2017) showed that the hydro-climatology of flood events in this region reflects a mixture of flood agents, consisting of thunderstorms and tropical cyclones. The largest fraction of events in the upper tail of flood distributions for basins in this area is associated with organized thunderstorms, which could explain the spatially concentrated nature of storm cores over LSugar Creek subbasins. Table 2 shows the degree of overlap in selected storm events between the five (sub)basins. The table shows that 54 to $69 \%$ of events in the largest basin (Lower LSugar) is represented in the flood event catalog for the smaller basins (first row), indicating that these events are likely to have been large-scale events, affecting the entire basin. Overlap between flood-producing events in Upper Briar and Lower Briar is $59 \%$. The lowest overlap occurs for LHope, indicating that a substantial part of flood events in this smaller basin is associated with a different collection of storm events compared to the other basins. As we can see in Fig. 2, a higher degree of overlapping storms between basins does not result in more similar rainfall or flow patterns: rainfall and flow characteristics are as similar or dis- 

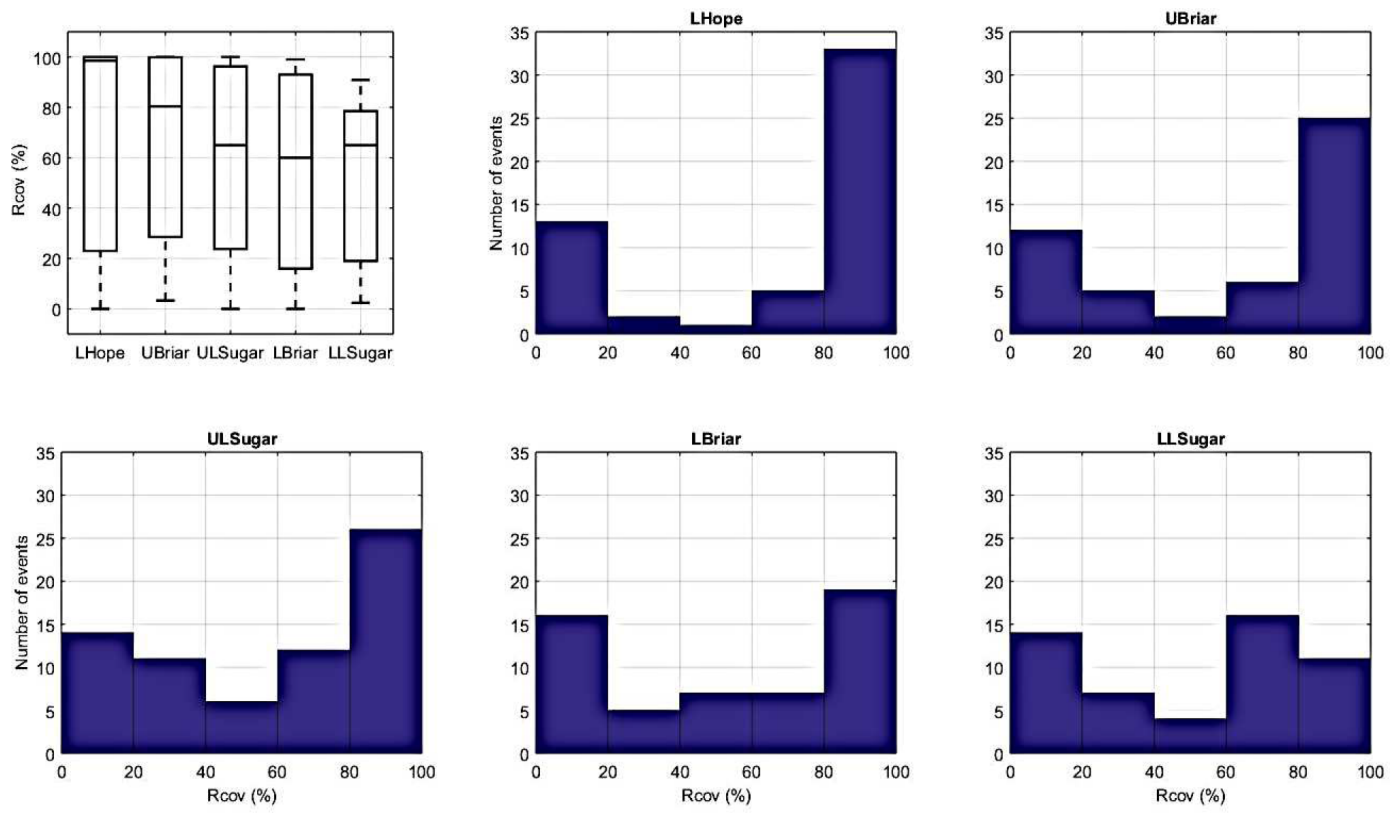

Figure 3. Box plots showing 10, 25, 50, 75 and $90 \%$ quantiles (a) and empirical histograms (b) of fractional basin coverage by maximum rainfall intensities $>25 \mathrm{~mm} \mathrm{~h}^{-1}$, representative of the storm core, for the five basins in the Little Sugar Creek catchment.

Table 2. Overlap in top flood producing storms for the five basins in Little Sugar Creek catchment, absolute numbers of events.

\begin{tabular}{lrrrrr}
\hline $\begin{array}{l}\text { Basin } \\
\text { name }\end{array}$ & LLSugar & LBriar & ULSugar & UBriar & LHope \\
\hline LLSugar & 52 & 36 & 36 & 32 & 28 \\
LBriar & & 54 & 30 & 32 & 21 \\
ULSugar & & & 69 & 30 & 34 \\
UBriar & & & & 50 & 20 \\
LHope & & & & & 54 \\
\hline
\end{tabular}

similar for Upper compared to Lower LSugar Creek as they are for LHope and UBriar or other sets of non-overlapping basins. Even if flood events in different catchments are generated by the same rainfall events, the characteristics of the rainfall as it affects the catchments is very different.

Figure 4 shows scatter plots of fractional coverage versus peak flow. The plots show that there is a tendency for peak flows to increase with fractional coverage and that the top peak flow values are generally associated with $100 \%$ basin coverage by the storm core. This confirms results found by Smith et al. (2002), who concluded that the relation between storm scale and basin was an important driver for flood response, and Syed et al. (2003), who found that areal coverage of the storm core was better correlated with runoff than area coverage of the entire storm. Our results show that for the urbanized basins in Little Sugar Creek, some of the highest peak flows (top 10 events in flood catalog) occur for fractional coverage well below $100 \%$. This could be associated with urbanization effects changing the upper tail of the peak flow distribution, as was suggested by Zhou et al. (2017), resulting in a different representation of storm events in the highest quantile peak flows.

We analyzed relationships between fractional coverage and rainfall intensity to see whether changes in basin-average rainfall are strongly tied to change in fractional coverage by the storm core, associated with the storm core moving into or out of the basin. Spearman rank correlation between firstorder differences in rainfall intensity and rainfall coverage with time $\left(\Delta R / \Delta t\right.$ versus $\left.\Delta R_{\operatorname{cov}} / \Delta t\right)$ were significant for all basins, with correlation values varying between 0.38 and 0.69 . This confirms that for the selected set of largest flow events in these basins, change in fractional coverage by the storm core is an important driver for change in basin-average rainfall intensity.

\subsection{Rainfall position and movement relative to flow-path network and effects on hydrological response}

An important aim of this study was to investigate how position and movement of rainfall in relation to the flow-path network, influences hydrological response. Figure 5 shows time-series of basin-average rainfall, fractional coverage by storm core $\left(>25 \mathrm{~mm} \mathrm{~h}^{-1}\right)$ and normalized RWD and RWD dispersion for two selected events in Lower LSugar basin. The two events (Fig. 5a and b) represent events from the top 10 highest peak flows in this basin. The third row in the figure illustrates development of normalized RWD as a function of time, the dashed line shows the flow distance for uniform 

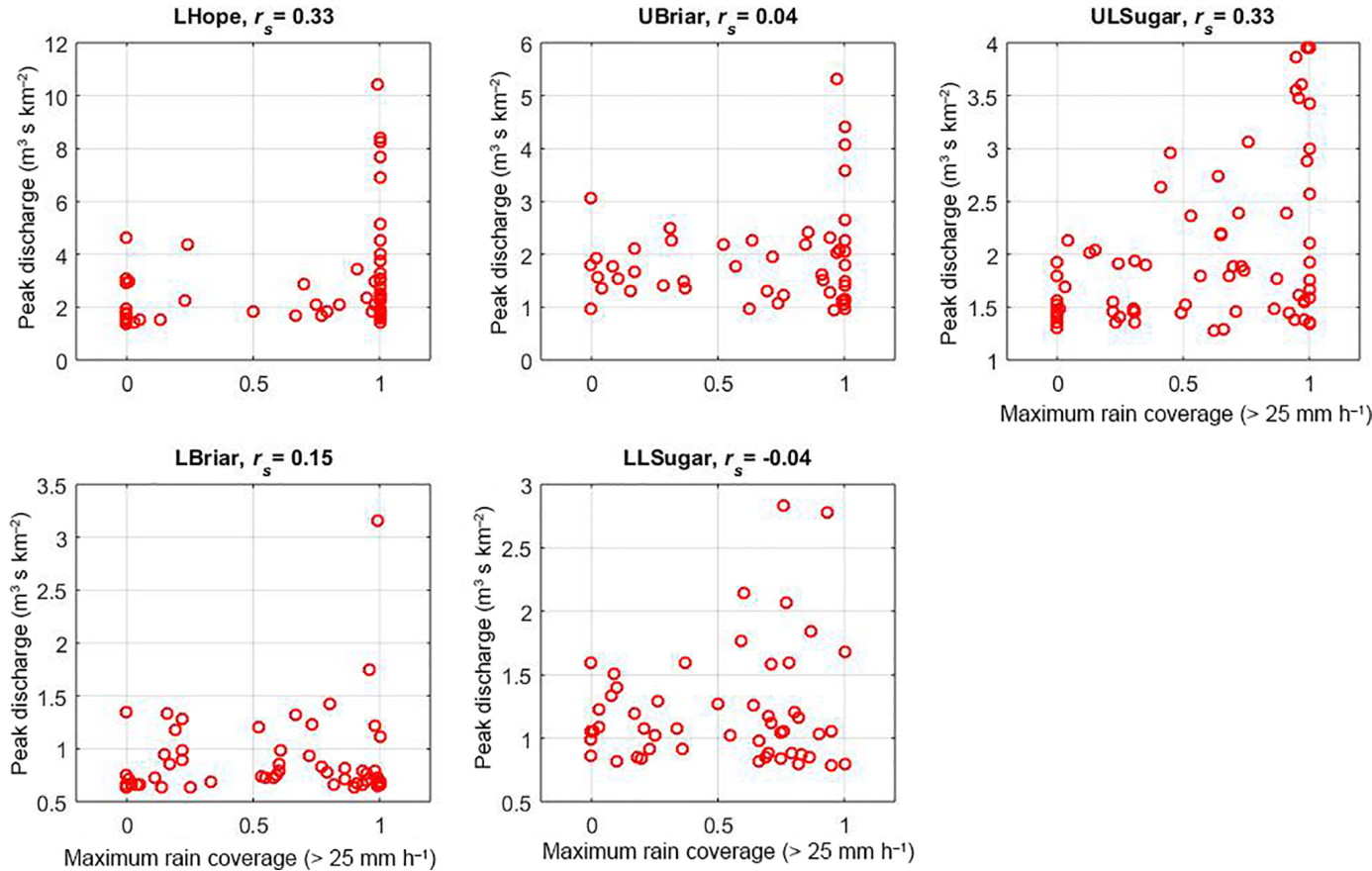

Figure 4. Scatter plots of basin fractional coverage by rainfall intensities $>25 \mathrm{~mm} \mathrm{~h}^{-1}$ versus peak flow, per event, for the five basins in Little Sugar Creek catchment and associated values for Spearman rank correlation coefficients.

rainfall, 0.53. The figure shows that normalized RWD values vary in a relatively small range around the mean: mean values are 0.41 and 0.40 , for a $3 \mathrm{~h}$ time window centered on the rainfall peak. Associated coefficient of variation values are 0.30 and 0.23 . This indicates that, on average, rainfall was concentrated slightly closer to the basin outlet compared to uniform rainfall. Normalized RWD dispersion shows whether rainfall is distributed uniformly, unimodally or multimodally with respect to the flow-path network (see also Eq. 12). Mean normalized RWD dispersion values are 0.83 and 0.93 , for a $3 \mathrm{~h}$ window centered on the rainfall peak. Maximum normalized RWD dispersion is 1.04 for the first and 1.39 for the second event. This indicates that on average rainfall was mildly concentrated in space compared to uniform rainfall, the first event being more unimodal and concentrated in space during the peak of the storm and the second event breaking into a multimodal structure in between the two rainfall peaks. Storm movement relative to the flow-path network can be derived from the time series of normalized RWD, by analyzing gradients in RWD over time. As Fig. 5 shows, normalized RWD was more or less constant during the period of the most intense rainfall for the first event (cf. period with rainfall intensities $>25 \mathrm{~mm} \mathrm{~h}^{-1}$ ), indicating that storm position relative to the flow-path network changed little during the event. For the second event, RWD decreased from 0.64 to 0.24 , the main decrease happening at the same time rainfall intensities decreased. This implies that the storm moved into the basin at the upstream end of the flow-path network and moved towards the outlet at the end of the event, to about
0.24 of the maximum flow distance (storm centered over the outlet corresponds to flow distance value of zero).

\subsubsection{Relationship between storm position relative to flow-path network and hydrological response}

Figure 6 shows box plots of normalized RWD values for event-total accumulated rainfall depth (Fig. 6a) and for the mean and gradient of $2 \mathrm{~h}$ temporally varied RWD (Fig. 6b and c) for the five basins. Results show that differences in normalized RWD between events tend to be small: 25-75\% ranges smaller than 0.1 for many of the basins. Differences increase with a combination of basin size and shape: the largest $25-75$ and 10-90\% ranges occur for Upper LSugar, the most elongated basin (see compactness values Table 1). This effect is emphasized for normalized RWD dispersion, where median values are lower and percentile ranges are much higher for the larger and elongated basins than for the two smallest basins (Fig. 6c). These results show that spatial rainfall variability is strongly smoothed by the flow-path network and that distribution of rainfall-weighted flow distances tends to be near uniform for the smallest basins. This suggests that the position of the storm relative to the flow-path network is likely to affect hydrological response, mainly in the larger basins. Relatively more spatially unimodal events occur in the larger and more elongated basins (Fig. 6c), yet this does not result in large differences in position along the flow-path network, as indicated by normalized RWD. 

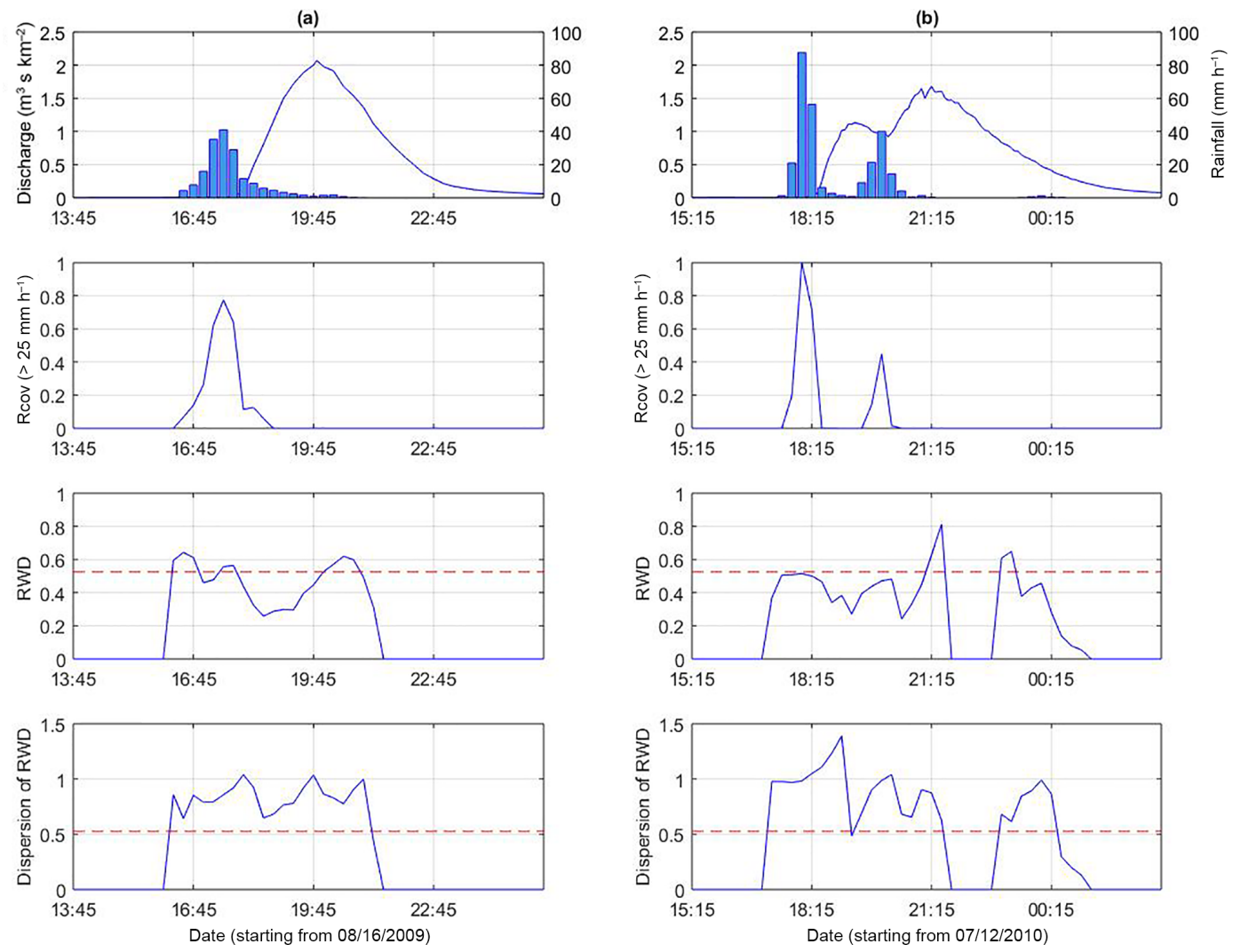

Figure 5. Time series of basin-average rainfall, flow, portion of basin covered by high-intensity rainfall $(>25 \mathrm{~mm} \mathrm{~h}-1)$, normalized rainfall-weighted flow distance (RWD) and RWD dispersion in Lower LSugar, for two events that occurred on 16 August 2009 (a) and 12 July 2010 (b).

Figure 7a shows a scatter plot of RWD computed for total accumulated rainfall depth per storm event versus lag time. For the smaller basins, no clear signal can be observed, yet for the larger basins (Lower Briar and Lower LSugar), lag time was significantly and positively correlated with stormtotal RWD. This indicates that in these basins, storm events concentrating in the upstream parts of the flow-path network are associated with longer lag times. No significant correlations with peak flow were found, as shown in Table 3, which summarizes Spearman rank correlation values between storm-total RWD ( $\mathrm{RWD}_{\text {tot }}$ ) and hydrological response characteristics, peak flow and lag time.

\subsubsection{Relationship between storm movement relative to flow-path network and hydrological response}

In this section we investigate how the combination of storm position and movement in time influence hydrological response. We analyzed correlations with peak flow and lag time for minimum, mean, maximum and gradient in normalized RWD over a range of time windows. Table 3 summarizes correlation values for peak flow and lag time, in relation to rainfall depth, rainfall intensity and RWD. The highest correlations were found for rainfall depth and maximum inten- sity; significant correlations were found for mean RWD and peak flow (LHope, ULSugar, LLSugar), for mean RWD and lag time (LBriar), and for gradient in RWD with lag time (UBriar, LLSugar). Figure 7b shows a scatter plot of maximum RWD versus peak flow; the plot shows there is no clear relationship between RWDmax and flow peak in LHope, UBriar and LBriar, either because the scale of these basins is too small compared to the scale of most storms (LHope) or because spatial rainfall variability is strongly smoothed by the basin (UBriar, LBriar). In ULSugar and LLSugar, the highest peak flows occur for storms that concentrate over the central and downstream parts of the basin, resulting in a negative correlation. A possible explanation for the negative correlation between RWD and peak flow for the Upper and Lower LSugar basins is the spatial distribution of impervious areas associated with the urban core of Charlotte. This will be analyzed in more detail in Sect. 3.4. No significant correlations between RWD and peak flow were found for Upper and Lower Briar, which suggests that spatial rainfall distribution does not influence peak flows, possibly due to a strong smoothing effect of the flow-path network in these basins. Figure $7 \mathrm{c}$ shows that large peak flows tend to occur for gradients near zero, i.e. slow-moving, near-stationary storms (relative to the flow-path network) or moving storms of larger 

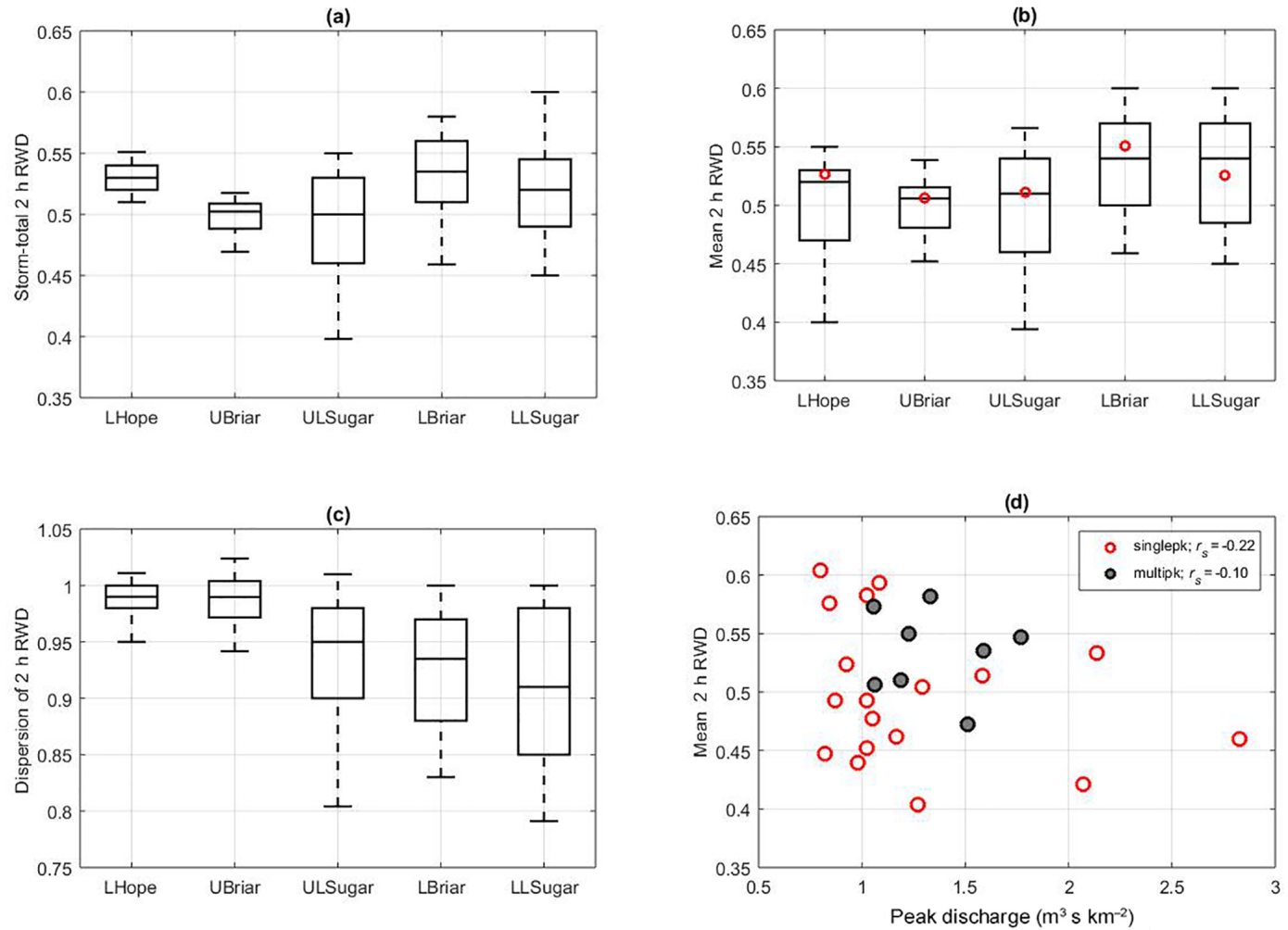

Figure 6. Box plots of RWD values for storm total rainfall (a); mean RWD for a $2 \mathrm{~h}$ window (b) and RWD dispersion for a $2 \mathrm{~h}$ window (c), for all events, for the five basins; scatter plot of mean RWD versus peak flow (d), for Lower LSugar, distinguishing between events with single and with multiple flow peaks. Red circles in box plots indicate RWD associated with spatially uniform rainfall.

Table 3. Summary of correlations between both peak flow $\left(Q_{\text {peak }}\right)$ and lag time $\left(T_{\text {lag }}\right)$ and total basin-average rainfall ( $\left.R_{\text {tot }}\right)$, peak rainfall intensity $\left(R_{\max }\right)$, normalized RWD associated with storm event total accumulated rainfall (RWD tot), mean normalized RWD for a $2 \mathrm{~h}$ time window $\left(\mathrm{RWD}_{\mathrm{m}}\right)$ and gradient in RWD for a $2 \mathrm{~h}$ time window (RWDgrad).

\begin{tabular}{lrrrrr|rrrr}
\hline \multirow{2}{*}{ Basin } & \multicolumn{4}{c}{ Peak flow } & \multicolumn{3}{c}{ Lag time } \\
\cline { 2 - 10 } Name & vs. $R_{\text {tot }}$ & vs. $R_{\max }$ & vs. RWD tot & vs. RWD & vs. RWD & vs. $R_{\text {tot }}$ & RWD $_{\text {tot }}$ & vs. RWD & vs. RWD \\
\hline LHope & $0.30^{*}$ & $0.40^{*}$ & 0.07 & $0.31^{*}$ & 0.09 & $0.39^{*}$ & 0.20 & 0.18 \\
UBriar & $0.32^{*}$ & $0.33^{*}$ & 0.14 & -0.03 & -0.03 & $0.31^{*}$ & 0.12 & -0.15 & -0.08 \\
ULSugar & $0.49^{*}$ & $0.43^{*}$ & -0.18 & $-0.27^{*}$ & $-0.32^{*}$ & $0.29^{*}$ & 0.05 & -0.08 & -0.20 \\
LBriar & $0.53^{*}$ & $0.38^{*}$ & 0.08 & 0.06 & -0.05 & $0.56^{*}$ & $0.41^{*}$ & $0.25^{*}$ & -0.09 \\
LLSugar & $0.48^{*}$ & $0.32^{*}$ & -0.16 & $-0.29^{*}$ & -0.23 & $0.43^{*}$ & $0.32^{*}$ & 0.05 & $-0.49^{*}$ \\
\hline
\end{tabular}

* Indicates significant correlations at the $5 \%$ level.

size than the basin area (especially for smaller basins like LHope).

We separately investigated correlations between rainfallweighted flow distance and hydrological response for a subset of clear, single-peak events, to exclude more complex correlation patterns associated with multi-peak events. Singlepeak events tend to show slightly higher correlations compared to multi-peak events, between rainfall properties or rainfall-weighted flow distances and peak flow or lag time (Fig. 6d). We also investigated whether correlations were different for small-scale storms compared to large-scale storms, by splitting the storm catalog into events with maximum rainfall coverage $>25 \mathrm{~mm} \mathrm{~h}^{-1}$ above and below $50 \%$. Correlation values for the two subsets improved for some cases, but improvements were not consistent across different basins. Finally, we investigated correlations for a subset of the storm event catalog, with a strong relation between storm movement and rainfall-weighted flow distance, as indicated by a strong correlation between the two, implying that change in rainfall intensity is closely associated with rainfall moving across the basin. The number of events with significant $\Delta R_{\mathrm{b}} / \Delta t$ versus $\Delta D_{\mathrm{Rw}} / \Delta t$ correlation varied from 12 for 

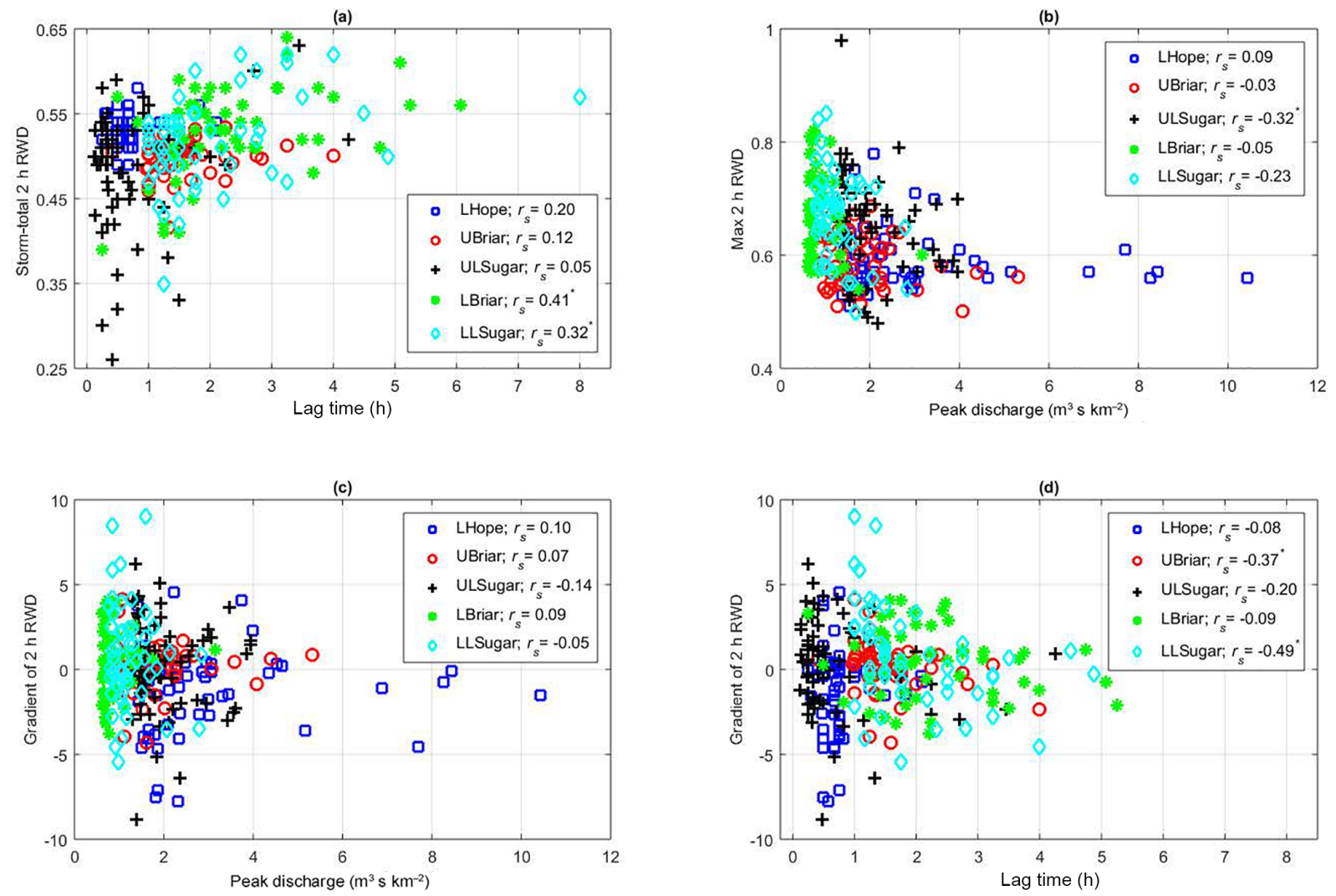

Figure 7. Scatter plots for storm-total RWD ( $2 \mathrm{~h}$ window) versus lag time (a), maximum RWD ( $2 \mathrm{~h}$ window) versus peak flow (b), gradient in RWD ( $2 \mathrm{~h}$ window) versus peak flow (c) and gradient in RWD ( $2 \mathrm{~h}$ window) versus lag time (d).

Lower Briar to 22 for Upper LSugar, i.e. 22 to $34 \%$ of the storm catalog. Generally, correlations with peak flow and lag time improved, indicating that storm movement into and out of the basin, leading to changes in basin-average rainfall intensity, significantly contributes to an explanation of the variability in hydrologic response. Investigations for event subsets served as a first exploration of potential multivariate relationships in the datasets. Results showed that explaining variability in hydrological response based on rainfall-weighted flow distance is more straightforward for single-peak events than for multi-peak events and that storm movement into and out a basin plays a significant role in explaining variability in hydrological response.

Table 3 shows that lag time was significantly negatively correlated with gradient in RWD associated with storm movement, for Upper Briar and Upper and Lower LSugar. This implies that storms moving faster towards the basin outlet were associated with slightly shorter lag times. Figure 7d shows that the relationship with RWD gradient is more subtle: small (near zero) gradients tend to be associated with longer lag times, while fast-moving storms tend to be associated with short lag times. Negative correlation with lag time is explained by negative gradients dominating over positive gradients. No significant correlations were found be- tween dispersion of rainfall-weighted flow distance and peak flow or lag time, showing that temporal variability in unior multimodality of storm events does not have a significant influence on hydrological response.

In this section we analyzed the influence of the position and movement of storms relative to the flow-path network on hydrological response. Results showed that spatial rainfall variability was strongly smoothed by the flow-path network, confirming similar results found by Smith et al. (2005) for a small $\left(14.3 \mathrm{~km}^{2}\right)$ basin. We found that, in small basins, rainfall concentrated in the upstream part of the basins was associated with higher peak flows, while in larger basins rainfall concentrated near the outlet was associated with significantly higher peak flows. Correlations were of the same order of magnitude or slightly weaker than those between total rainfall depth or peak rainfall intensity and peak flow. This confirms results found by Smith et al. (2002), who found that for only one of five storms they analyzed, storm position and movement amplified peak flow. While Syed et al. (2003) found that the importance of storm position increased with basin size, this effect was not clearly visible for the basins we investigated in our study. Slow-moving, nearstationary storms (relative to the flow-path network) were associated with longer lag times in some but not all basins; 
(a)

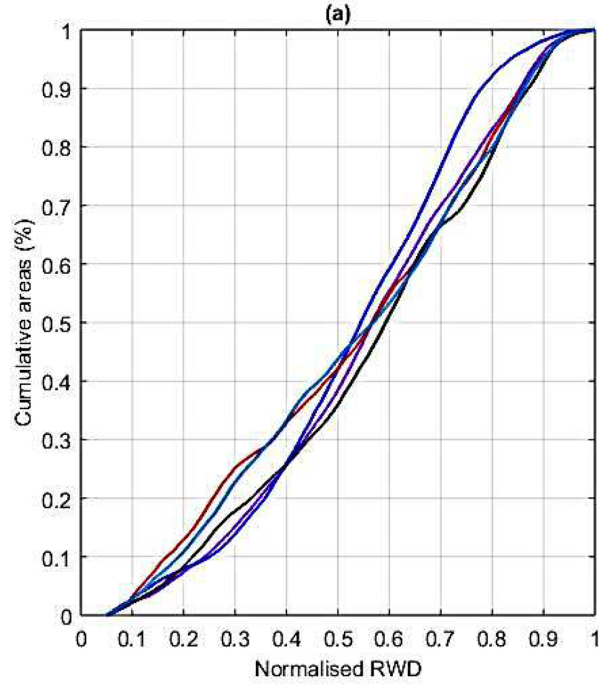

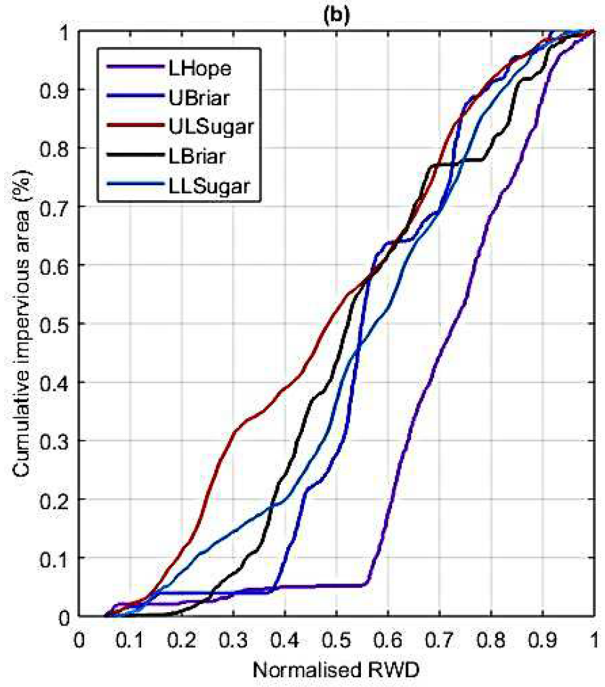

Figure 8. Cumulative distribution of catchment area (a) and of impervious areas (b) as a function of distance along the flow-path network, for the five basins in Little Sugar Creek catchment.

near-stationary storms also tend to be associated with higher peak flows. Earlier studies have surmised sensitivity of hydrological response to storm position and movement to be highest when computed over time windows equal to the basin lag time (Zoccatelli et al., 2011; Nikolopoulos et al., 2014). In our analyses, we found no relation between the time windows for computation of storm position or movement and basin response time.

\subsection{Spatial distribution of impervious areas, spatial rainfall variability and hydrological response}

Spatial distribution of rainfall in relation to the distribution of impervious areas in the basins is expected to have an influence on peak flow and lag time, since rainfall on impervious areas generates relatively more runoff and runs off faster compared to pervious areas. The degree of interaction between spatial rainfall variability and spatial imperviousness distribution is likely to depend on two factors: degree of impervious cover in a basin and degree of spatial variation in imperviousness. Figure 8a shows the cumulative distribution of basin area as a function of distance along the flow-path network for the five basins in Little Sugar Creek. Figure 8b shows the cumulative distribution for impervious areas. Gradients steeper than the 1-1 line indicate where impervious areas are relatively concentrated along the flow-path network.

Imperviousness is most inhomogeneously distributed for LHope, where it is almost entirely concentrated in the upstream part of the basin (above 0.55 normalised distance along the flow-path network). In Upper Briar, impervious areas are more concentrated between 0.4 and 0.6 normalized RWD. In Upper LSugar, imperviousness is nearly homogeneously distributed along the flow-path network. In Lower LSugar and Lower Briar, impervious areas are slightly more concentrated near and just downstream of the mean flow-path distance.

We analyzed the influence of spatial rainfall variability in relation to the distribution of impervious areas based on a binary weighting of normalized RWD by imperviousness, $D_{I}(t)$, as described in Sect. 2.2.2. We found that differences in normalized RWD between events increased by imperviousness weighting only for the smallest basin, LHope, while they remained more or less neutral for Upper Briar and Upper LSugar and slightly decrease for Lower Briar and Lower LSugar. This is illustrated in the scatter plots for RWD and imperviousness-weighted RWD versus peak flow in Fig. 9. We analyzed influence of imperviousness on hydrological response based on Spearman correlations among imperviousness-weighted RWD, peak flow and lag time. As Fig. 9 shows, relationships between imperviousnessweighted RWD and peak flow changed little or decreased slightly compared to those based on total basin area. The overall effect was that correlations based on imperviousnessweighted RWD for both peak flow and lag time were weak and no longer significant at the 5\% level. This shows that position of the storm relative to impervious cover within the basins had little effect on flow peaks. This was mainly due to imperviousness being relatively homogeneously distributed in four of the five basins; by contrast, for LHope, Fig. 9 shows that higher flow peaks were all associated with rainfall over the upper part of the basin, where imperviousness is concentrated. Future studies covering a wider range of basin scales and variability in impervious cover will be needed, to investigate to what extent this conclusion holds for other urbanized basins and what combinations of storm scales and imperviousness distribution lead to sensitivity of peak flows to impervious cover. Apart from impervious cover, the effect of 
spatial distribution of urban soils with relatively lower permeability than natural soils can be analyzed using the same approach. This will provide better insights into characteristic imperviousness cover and variability scales that determine sensitivity of hydrological response to spatial rainfall variability.

\section{Summary and conclusions}

The objective of this study was to provide insights into how spatial and temporal rainfall variability interact with catchment scale and flow-path network structure to generate hydrological response in urbanized basins, based on extensive observational datasets. The study comprised analysis of a catalog of the largest 279 flood events extracted from 15 years of rainfall and flow data over 5 nested basins of varying size and degree of urban development. We analyzed rainfall coverage over the basin and over impervious areas in the basin to analyze spatial variability effects on peak flow and lag time. We used the concept of rainfall-weighted flow distance introduced by Smith et al. (2002) to analyze how storm position and movement relative to the flow-path network influenced hydrological response. The following conclusions were drawn from the analyses.

1. Catchment scale determines the type of storm events that produce largest peak flows at the catchment outlet: storm events for the catalog of the largest peak flows in the small $\left(7 \mathrm{~km}^{2}\right)$ basin show only $39-54 \%$ overlap with those for the larger basins. The largest overlap in storm events, $69 \%$, is found for the two largest basins, 48.5 and $111.1 \mathrm{~km}^{2}$ in size. This confirms results reported by Smith et al. (2013b) and Zhou et al. (2017), who also found markedly different rainfall climatologies for flood-producing storms in basins of different size.

2. Catchment scale determines the degree of variability in peak flows and peak rainfall intensities for the catalog of largest flood events. Coefficients of variation in peak flows vary from 0.46 for the largest to 0.65 for the smallest basin. The lowest flow variability is found for the most urbanized basin (size $31.5 \mathrm{~km}^{2}$ ), which suggests a smoothing effect of imperviousness on flow variability. Similar results were found by other authors and were attributed to the effect of constraints in the drainage network (Smith and Smith, 2015; Ten Veldhuis and Schleiss, 2017).

3. Scale of the storm core, measured by maximum coverage of a basin by rainfall intensities above $25 \mathrm{~mm} \mathrm{~h}^{-1}$, varies strongly with basin scale: for the smallest $\left(7 \mathrm{~km}^{2}\right)$ basin, intense storm cores exceed basin scale for $43 \%$ of the storms, while $30 \%$ of the storms cover less than half of the basin. For the largest basin, storm cores exceed basin scale for only $2 \%$ of the storms and
$44 \%$ of events cover less than half the basin area. Empirical histograms of rainfall coverage for intensities above $25 \mathrm{~mm} \mathrm{~h}^{-1}$ show that for the smaller basins, up to $31.5 \mathrm{~km}^{2}$, storm events largely fall into two groups: large-scale events, with intense storm cores exceeding basin-scale and small-scale events, with storm cores covering less than $20 \%$ of the basin.

4. Dynamics of rainfall coverage by the storm core are an important driver for temporal variability of basinaverage rainfall. Spearman rank correlation between first-order differences in rainfall intensity and rainfall coverage with time $\left(\Delta R / \Delta t\right.$ versus $\left.\Delta R_{\text {cov }} / \Delta t\right)$ were significant for all basins; correlation values varying between 0.38 and 0.69 . This suggests that storm movement over the basin drives increases and decreases in basin-average rainfall intensity more strongly than development of storm cells during storm passage over the basin.

5. There is a tendency for peak flows to increase with fractional coverage and the highest peak flow values are generally associated with $100 \%$ basin coverage by the storm core. This confirms results found by Smith et al. (2002), who concluded that the relation between storm scale and basin was an important driver for flood response, and Syed et al. (2003), who found that areal coverage of the storm core was better correlated with runoff than area coverage of the entire storm. Our results also show that for the urbanized basins in Little Sugar Creek, some of the highest peak flows (top 10 events in flood catalog) occur for fractional coverage well below $100 \%$. This could be associated with urbanization effects changing the upper tail of the peak flow distribution, as was suggested by Zhou et al. (2017), resulting in a different representation of storm events in the highest quantile peak flows.

6. The combination of spatial rainfall structure and flowpath network (expressed in terms of rainfall-weighted flow distance) plays a smaller role in explaining variability in hydrological response compared to rainfall volume and peak intensity. This could be explained by spatial rainfall variability having a relatively small contribution to flow variability compared to climatological rainfall variability, as shown by Peleg et al. (2017). Another explanation is that spatial rainfall variability is strongly smoothed by the flow-path network, as was also shown in earlier studies for a more limited range of observations (Smith et al., 2005).

7. The role of storm movement relative to the flow-path network is investigated based on temporal gradients in rainfall-weighted flow distance. Movement of storms upstream or downstream along the main axis of the flow-path network have no significant influence on peak 

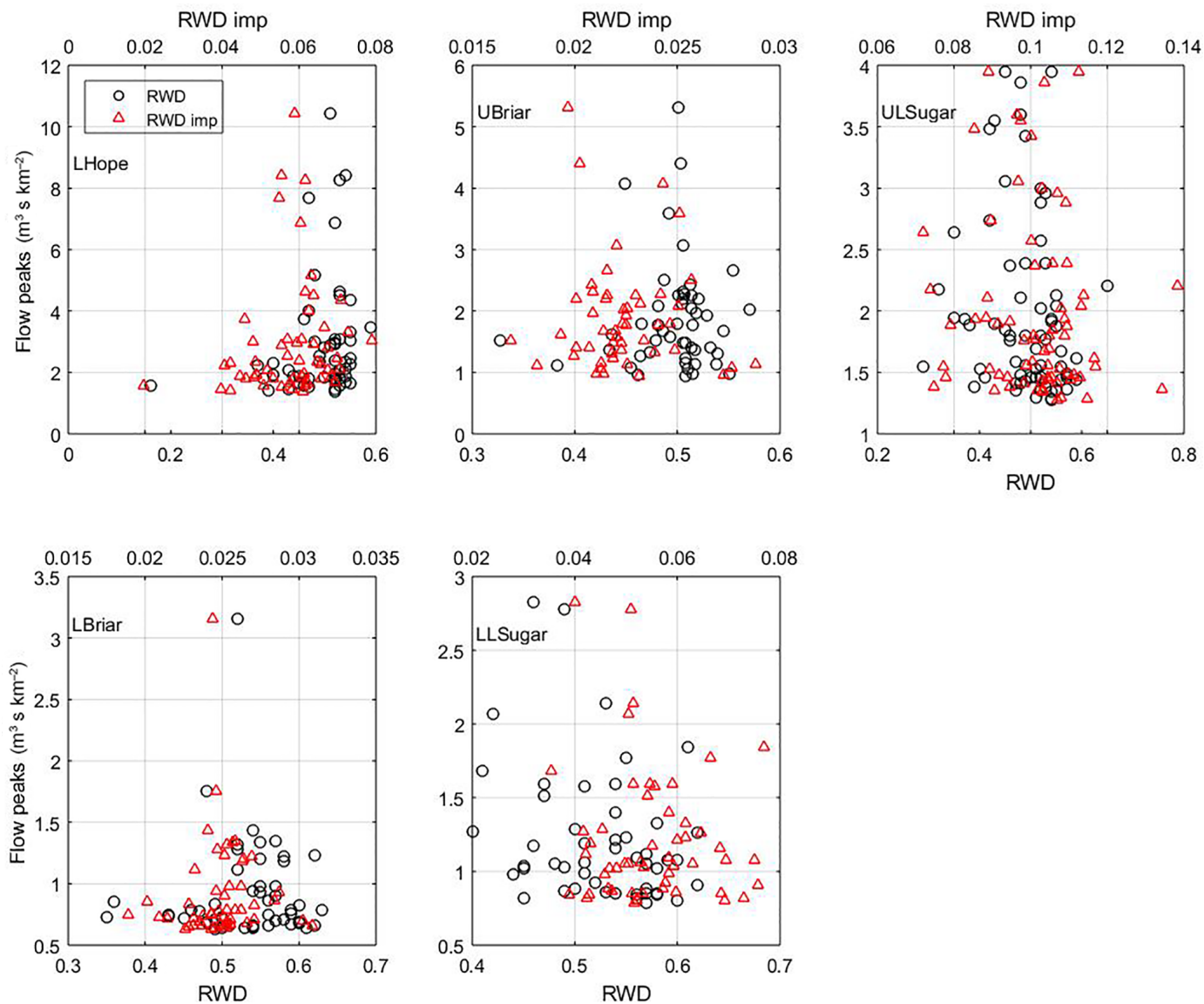

Figure 9. Scatter plots of 2 h-mean RWD versus peak flow, for RWD based on all areas (lower $x$ axis) and for normalized RWD weighted by imperviousness (upper $x$ axis), for the five basins in LSugar Creek catchment.

flows. Slow-moving, (near) stationary storms relative to the flow-path network tend to be associated with higher peak flows. Additionally, slow-moving storms are generally associated with longer lag times.

8. The impact of spatial variability in urban land cover on hydrological response is investigated based on rainfallweighted flow distance over impervious areas. We find that position of the storm relative to impervious cover within the basins had little effect on flow peaks. A possible explanation is that for the largest basins, where spatial rainfall variability is higher, imperviousness is relatively homogenously distributed, and more smoothing by the flow-path network occurs. By contrast, for the smallest basin, where imperviousness is concentrated in the upper part of the basins, the highest peak flows were all associated with rainfall over this part of the basin.

Results of this study, based on 279 flood events for a range of basin sizes, clearly show that the relation between rainfall and basin scales is an important driver for generating the largest peak flows. Rainfall spatial structure and storm movement seem to play a less important role, being strongly smoothed by the flow-path network. Additional analyses for a larger number of basins are needed to further look into the role of storm position and movement in generating hydrological response. Additionally, the influence of spatial variability in impervious cover on peak flows and lag time needs further investigation to better understand the interplay between the spatial distribution of rainfall and urbanization. The role of other spatially variable catchment characteristics like topography and (urban) soil properties have not been considered in this study. In a recent study by Zhou et al. (2017) the effect of antecedent watershed wetness was investigated for the Charlotte region. They did not find a significant influence of antecedent rainfall on flood response. Direct observations of soil moisture content could help to shed more light on the effect of soil moisture in urban regions and how that affects hydrological response. The importance of variability in topography, soil moisture and urbanization in relation to spatial rainfall variability and climatological variability remain important topics for future research. Future work will focus on analyses for a larger number of basins and a larger set of storms, including smaller, more concentrated storms relative to the catchment scale, to investigate the role of spatial rain- 
fall variability compared to climatological rainfall variability in explaining hydrological response.

Data availability. Flow data used in this study are open datasets made publicly available by USGS. They are available at http: //waterdata.usgs.gov/nc/nwis (USGS, 2016). The following is a link to flow gauges in Mecklenburg County, used in our study: https://waterdata.usgs.gov/nc/nwis/uv?referred_module. The radar rainfall data used in this study are archived at Princeton University and can be made available through the authors upon request.

Competing interests. The authors declare that they have no conflict of interest.

Acknowledgements. Flow data used in this study are available at http://waterdata.usgs.gov/nc/nwis. The radar rainfall data used in this study can be made available upon request. We are grateful to Mary Lynn Baeck for making available the NEXRAD radar rainfall datasets used in this study. We would like to thank Julia Signel for organizing the USGS flow datasets for the hydrological basins in Charlotte. The first author would like to thank NWO Aspasia and Delft University of Technology for the grant that supported this research collaboration. The authors would like to acknowledge support for this research from the National Science Foundation (CBET-1444758 and AGS-1522492).

Edited by: Thomas Kjeldsen

Reviewed by: Søren Thorndahl and two anonymous referees

\section{References}

Anquetin, S., Braud, I., Vannier, O., Viallet, P., Boudevillain, B., Creutin, J.-D., and Manus, C.: Sensitivity of the hydrological response to the variability of rainfall fields and soils for the Gard 2002 flash-flood event, J. Hydrol., 394, 134-147, https://doi.org/10.1016/j.jhydrol.2010.07.002, 2010.

Bell, C., McMillan, S., Clinton, S., and Jefferson, A.: Hydrologic response to stormwater control measures in urban watersheds, J. Hydrol., 541, 1488-1500, https://doi.org/10.1016/j.jhydrol.2016.08.049, 2016.

Berne, A. and Krajewski, W.: Radar for hydrology: Unfulfilled promise or unrecognized potential?, Adv. Water Resour., 51, 357-366, https://doi.org/10.1016/j.advwatres.2012.05.005, 2013.

Berne, A., Delrieu, G., Creutin, J.-D., and Obled, C.: Temporal and spatial resolution of rainfall measurements required for urban hydrology, J. Hydrol., 299, 166-179, https://doi.org/10.1016/j.jhydrol.2004.08.002, 2004.

Bruni, G., Reinoso, R., Van De Giesen, N., Clemens, F., and Ten Veldhuis, J.: On the sensitivity of urban hydrodynamic modelling to rainfall spatial and temporal resolution, Hydrol. Earth Syst. Sci., 19, 691-709, https://doi.org/10.5194/hess-19691-2015, 2015.

Chen, H. and Chandrasekar, V.: The quantitative precipitation estimation system for Dallas-Fort Worth (DFW) ur- ban remote sensing network, J. Hydrol., 531, 259-271, https://doi.org/10.1016/j.jhydrol.2015.05.040, 2015.

Cheng, S.-J. and Wang, R.-Y.: An approach for evaluating the hydrological effects of urbanization and its application, Hydrol. Process., 16, 1403-1418, https://doi.org/10.1002/hyp.350, 2002.

Du, J., Qian, L., Rui, H., Zuo, T., Zheng, D., Xu, Y., and Xu, C.Y.: Assessing the effects of urbanization on annual runoff and flood events using an integrated hydrological modeling system for Qinhuai River basin, China, J. Hydrol., 464/465, 127-139, https://doi.org/10.1016/j.jhydrol.2012.06.057, 2012.

Emmanuel, I., Andrieu, H., Leblois, E., Janey, N., and Payrastre, O.: Influence of rainfall spatial variability on rainfall-runoff modelling: Benefit of a simulation approach?, J. Hydrol., 531, 337348, https://doi.org/10.1016/j.jhydrol.2015.04.058, 2015.

Fletcher, T., Andrieu, H., and Hamel, P.: Understanding, management and modelling of urban hydrology and its consequences for receiving waters: A state of the art, Adv. Water Resour., 51, 261279, https://doi.org/10.1016/j.advwatres.2012.09.001, 2013.

Gires, A., Onof, C., Maksimovic, C., Schertzer, D., Tchiguirinskaia, I., and Simoes, N.: Quantifying the impact of small scale unmeasured rainfall variability on urban runoff through multifractal downscaling: A case study, J. Hydrol., 442/443, 117-128, https://doi.org/10.1016/j.jhydrol.2012.04.005, 2012.

Hopkins, K., Morse, N., Bain, D., Bettez, N., Grimm, N., Morse, J., Palta, M., Shuster, W., Bratt, A., and Suchy, A.: Assessment of regional variation in streamflow responses to urbanization and the persistence of physiography, Environ. Sci. Technol., 49, 2724-2732, https://doi.org/10.1021/es505389y, 2015.

Huang, H.-J., Cheng, S.-J., Wen, J.-C., and Lee, J.-H.: Effect of growing watershed imperviousness on hydrograph parameters and peak discharge, Hydrol. Process., 22, 2075-2085, https://doi.org/10.1002/hyp.6807, 2008.

Krajewski, W. and Smith, J.: Radar hydrology: rainfall estimation, Adv. Water Resour., 25, 1387-1394, 2002.

Krajewski, W., Kruger, A., Smith, J., Lawrence, R., Gunyon, C., Goska, R., Seo, B.-C., Domaszczynski, P., Baeck, M., Ramamurthy, M., Weber, J., Bradley, A., DelGreco, S., and Steiner, M.: Towards better utilization of NEXRAD data in hydrology: An overview of Hydro-NEXRAD, J. Hydroinform., 13, 255266, https://doi.org/10.2166/hydro.2010.056, 2011.

Lobligeois, F., Andréassian, V., Perrin, C., Tabary, P., and Loumagne, C.: When does higher spatial resolution rainfall information improve streamflow simulation? An evaluation using 3620 flood events, Hydrol. Earth Syst. Sci., 18, 575-594, https://doi.org/10.5194/hess-18-575-2014, 2014.

Meierdiercks, K., Smith, J., Baeck, M., and Miller, A.: Heterogeneity of Hydrologic Response in Urban Watersheds, J. Am. Water Resour. As., 46, 1221-1237, https://doi.org/10.1111/j.17521688.2010.00487.x, 2010.

Miller, J., Kim, H., Kjeldsen, T., Packman, J., Grebby, S., and Dearden, R.: Assessing the impact of urbanization on storm runoff in a peri-urban catchment using historical change in impervious cover, J. Hydrol., 515, 59-70, https://doi.org/10.1016/j.jhydrol.2014.04.011, 2014.

Morin, E., Goodrich, D., Maddox, R., Gao, X., Gupta, H., and Sorooshian, S.: Spatial patterns in thunderstorm rainfall events and their coupling with watershed hydrological response, Adv. Water Resour., 29, 843-860, https://doi.org/10.1016/j.advwatres.2005.07.014, 2006. 
Nicotina, L., Alessi Celegon, E., Rinaldo, A., and Marani, M.: On the impact of rainfall patterns on the hydrologic response, Water Resour. Res., 44, 1-14, https://doi.org/10.1029/2007WR006654, 2008.

Niemczynowicz, J.: Urban hydrology and water management present and future challenges, Urban Water, 1, 1-14, 1999.

Nikolopoulos, E., Borga, M., Zoccatelli, D., and Anagnostou, E.: Catchment-scale storm velocity: Quantification, scale dependence and effect on flood response [Vitesse d'averse à l'échelle du bassin: Quantification, dépendance d'échelle et effets sur la crue correspondante], Hydrolog. Sci. J., 59, 1363-1376, https://doi.org/10.1080/02626667.2014.923889, 2014.

NOAA: NOAA atlas 14 point precipitation frequency estimates: NC, https://hdsc.nws.noaa.gov/hdsc/pfds/pfds_map_cont.html? bkmrk=nc (last access: 4 August 2017), 2017.

Ochoa-Rodriguez, S., Wang, L.-P., Gires, A., Pina, R., ReinosoRondinel, R., Bruni, G., Ichiba, A., Gaitan, S., Cristiano, E., Van Assel, J., Kroll, S., Murlà-Tuyls, D., Tisserand, B., Schertzer, D., Tchiguirinskaia, I., Onof, C., Willems, P., and Ten Veldhuis, M.-C.: Impact of spatial and temporal resolution of rainfall inputs on urban hydrodynamic modelling outputs: A multi-catchment investigation, J. Hydrol., 531, 389-407, https://doi.org/10.1016/j.jhydrol.2015.05.035, 2015.

Ogden, F., Raj Pradhan, N., Downer, C., and Zahner, J.: Relative importance of impervious area, drainage density, width function, and subsurface storm drainage on flood runoff from an urbanized catchment, Water Resour. Res., 47, W12503, https://doi.org/10.1029/2011WR010550, 2011.

Otto, T. and Russchenberg, H.: Estimation of specific differential phase and differential backscatter phase from polarimetric weather radar measurements of rain, IEEE Geosci. Remote Sens. Lett., 8, 988-992, https://doi.org/10.1109/LGRS.2011.2145354, 2011.

Peleg, N., Blumensaat, F., Molnar, P., Fatichi, S., and Burlando, P.: Partitioning the impacts of spatial and climatological rainfall variability in urban drainage modeling, Hydrol. Earth Syst. Sci., 21, 1559-1572, https://doi.org/10.5194/hess-21-1559-2017, 2017.

Rafieeinasab, A., Norouzi, A., Kim, S., Habibi, H., Nazari, B., Seo, D.-J., Lee, H., Cosgrove, B., and Cui, Z.: Toward high-resolution flash flood prediction in large urban areas Analysis of sensitivity to spatiotemporal resolution of rainfall input and hydrologic modeling, J. Hydrol., 531, 370-388, https://doi.org/10.1016/j.jhydrol.2015.08.045, 2015.

Rose, S. and Peters, N.: Effects of urbanization on streamflow in the Atlanta area (Georgia, USA): A comparative hydrological approach, Hydrol. Process., 15, 1441-1457, https://doi.org/10.1002/hyp.218, 2001.

Schilling, W.: Rainfall data for urban hydrology: what do we need?, Atmos. Res., 27, 5-21, https://doi.org/10.1016/01698095(91)90003-F, 1991.

Segond, M.-L., Wheater, H., and Onof, C.: The significance of spatial rainfall representation for flood runoff estimation: A numerical evaluation based on the Lee catchment, UK, J. Hydrol., 347, 116-131, https://doi.org/10.1016/j.jhydrol.2007.09.040, 2007.

Seo, B.-C., Krajewski, W., Kruger, A., Domaszczynski, P., Smith, J., and Steiner, M.: Radar-rainfall estimation algorithms of Hydro-NEXRAD, J. Hydroinform., 13, 277-291, https://doi.org/10.2166/hydro.2010.003, 2011.
Smith, B. and Smith, J.: The flashiest watersheds in the contiguous United States, J. Hydrometeorol., 16, 2365-2381, https://doi.org/10.1175/JHM-D-14-0217.1, 2015.

Smith, B., Smith, J., Baeck, M., Villarini, G., and Wright, D.: Spectrum of storm event hydrologic response in urban watersheds, Water Resour. Res., 49, 2649-2663, https://doi.org/10.1002/wrcr.20223, 2013a.

Smith, J., Baeck, M., Morrison, J., Sturdevant-Rees, P., TurnerGillespie, D., and Bates, P.: The regional hydrology of extreme floods in an urbanizing drainage basin, J. Hydrometeorol., 3, 267-282, https://doi.org/10.1175/15257541(2002)003<0267:TRHOEF>2.0.CO;2, 2002.

Smith, J., Baeck, M., Meierdiercks, K., Nelson, P., Miller, A., and Holland, E.: Field studies of the storm event hydrologic response in an urbanizing watershed, Water Resour. Res., 41, W10413, https://doi.org/10.1029/2004WR003712, 2005.

Smith, J., Baeck, M., Meierdiercks, K., Miller, A., and Krajewski, W.: Radar rainfall estimation for flash flood forecasting in small urban watersheds, Adv. Water Resour., 30, 2087-2097, https://doi.org/10.1016/j.advwatres.2006.09.007, 2007.

Smith, J., Baeck, M., Villarini, G., Wright, D., and Krajewski, W.: Extreme flood response: The june 2008 flooding in Iowa, J. Hydrometeorol., 14, 1810-1825, https://doi.org/10.1175/JHMD-12-0191.1, 2013b.

Syed, K., Goodrich, D., Myers, D., and Sorooshian, S.: Spatial characteristics of thunderstorm rainfall fields and their relation to runoff, J. Hydrol., 271, 1-21, https://doi.org/10.1016/S00221694(02)00311-6, 2003.

Ten Veldhuis, M.-C. and Schleiss, M.: Statistical analysis of hydrological response in urbanising catchments based on adaptive sampling using inter-amount times, Hydrol. Earth Syst. Sci., 21, 1991-2013, https://doi.org/10.5194/hess-21-1991-2017, 2017.

Tetzlaff, D. and Uhlenbrook, S.: Significance of spatial variability in precipitation for process-oriented modelling: results from two nested catchments using radar and ground station data, Hydrol. Earth Syst. Sci., 9, 29-41, https://doi.org/10.5194/hess-929-2005, 2005.

Thorndahl, S., Einfalt, T., Willems, P., Ellerbæk Nielsen, J., Ten Veldhuis, M.-C., Arnbjerg-Nielsen, K., Rasmussen, M., and Molnar, P.: Weather radar rainfall data in urban hydrology, Hydrol. Earth Syst. Sci., 21, 1359-1380, https://doi.org/10.5194/hess-21-1359-2017, 2017.

Turner-Gillespie, D., Smith, J., and Bates, P.: Attenuating reaches and the regional flood response of an urbanizing drainage basin, Adv.Water Resour., 26, 673-684, https://doi.org/10.1016/S03091708(03)00017-4, 2003.

USGS: National Water Information System: Web Interface, USGS Water Data for North Carolina: http://waterdata.usgs.gov/nc/ nwis, last access: 9 March 2017.

Villarini, G., Smith, J., Serinaldi, F., Bales, J., Bates, P., and Krajewski, W.: Flood frequency analysis for nonstationary annual peak records in an urban drainage basin, Adv. Water Resour., 32, 1255-1266, https://doi.org/10.1016/j.advwatres.2009.05.003, 2009.

Volpi, E., Di Lazzaro, M., and Fiori, A.: A simplified framework for assessing the impact of rainfall spatial variability on the hydrologic response, Adv. Water Resour., 46, 1-10, https://doi.org/10.1016/j.advwatres.2012.04.011, 2012. 
Wright, D., Smith, J., Villarini, G., and Baeck, M.: Estimating the frequency of extreme rainfall using weather radar and stochastic storm transposition, J. Hydrol., 488, 150-165, https://doi.org/10.1016/j.jhydrol.2013.03.003, 2013.

Wright, D., Smith, J., and Baeck, M.: Flood frequency analysis using radar rainfall fields and stochastic storm transposition, Water Resour. Res., 50, 1592-1615, https://doi.org/10.1002/2013WR014224, 2014a.

Wright, D., Smith, J., Villarini, G., and Baeck, M.: Long-term highresolution radar rainfall fields for urban hydrology, J. Am. Water Resour. As., 50, 713-734, https://doi.org/10.1111/jawr.12139, 2014b.

Yakir, H. and Morin, E.: Hydrologic response of a semi-arid watershed to spatial and temporal characteristics of convective rain cells, Hydrol. Earth Syst. Sci., 15, 393-404, https://doi.org/10.5194/hess-15-393-2011, 2011.
Yang, L., Smith, J., Baeck, M., and Zhang, Y.: Flash flooding in small urban watersheds: Storm event hydrologic response, Water Resour. Res., 52, 4571-4589, https://doi.org/10.1002/2015WR018326, 2016.

Zhou, Z., Smith, J., Yang, L., Baeck, M., Chaney, M., Ten Veldhuis, M.-C., Deng, H., and Liu, S.: The complexities of urban flood response: Flood frequency analyses for the Charlotte metropolitan region, Water Resour. Res., 53, 7401-7425, https://doi.org/10.1002/2016WR019997, 2017.

Zoccatelli, D., Borga, M., Viglione, A., Chirico, G., and Blöschl, G.: Spatial moments of catchment rainfall: Rainfall spatial organisation, basin morphology, and flood response, Hydrol. Earth Syst. Sci., 15, 3767-3783, https://doi.org/10.5194/hess-15-3767-2011, 2011. 